\title{
The consequences of retail electricity price rises - rethinking customer hardship
}

\author{
Paul Simshauser and Tim Nelson* \\ AGL Energy Ltd \\ Level 6, 144 Edward Street \\ Brisbane, QLD, 4001. \\ June 2012.
}

\begin{abstract}
The Australian energy sector is nearing the end of an investment megacycle, which has driven above-trend electricity tariff increases. In this article, we combine energy market and demographic data and find that dominant thought on customer hardship, aged pensioners, pales into insignificance by comparison to those in the family formation cohort, those known as Australia's 'working poor'. Our modelling results are clear in their implications; hardship policy for energy customers requires reengineering. The structure of electricity tariffs requires an overhaul - shifting to interval meters, time-ofuse pricing and monthly billing to redress the investment megacycle and the incidence of hardship.
\end{abstract}

Keywords: Electric Utilities, Electricity Prices, Customer Hardship.

JEL Codes: D61, L94, L11 and Q40.

\section{Introduction}

Over the 2009-2012 period, one of the defining characteristics of the September quarter release of Australia's Consumer Price Index has been the marked contribution of electricity tariff movements to headline inflation rates. In September 2012, default electricity tariffs rose $18.5 \%$ after the introduction of the carbon price. In September 2011, electricity tariffs increased by 7.8\%, following a 6.0\% rise in September 2010 and an 11.4\% rise in September 2009. ${ }^{1}$ Yet as a component cost of the average household wallet, energy bills have remained virtually constant for more than two decades at $2.6 \%$, as ABS data reveals. Declining consumption and income growth has evidently resulted in the average household maintaining 'share of wallet' expenditure on electricity. It is worth noting that other essential items such as housing (18\%), food and beverages (16.5\%) and transport (15.6\%) take up a substantially larger share of household income. In fact, Australian households consistently spend more on alcohol \& tobacco (3.6\%) than they do on energy.

Average household energy consumption has fallen by about $6.0 \%$ over the past two years. ${ }^{2}$ In our opinion, this contraction is partly the result of moderate weather (resulting in reduced heating and cooling loads), demand response to persistent tariff increases, more energy efficient appliances, housing insulation and the uptake of solar hot water and solar PV units. Additionally, household floor space, an important driver of spatial heating and cooling loads over the past two decades, has also finally reached a plateau - a result not surprising given Australia's incremental housing stock is now the largest in the world at 245 square meters (James, 2009). Media coverage

\footnotetext{
* Paul Simshauser is Chief Economist at AGL Energy Ltd and Professor of Economics at Griffith University. Tim Nelson is Head of Economics, Policy \& Sustainability at AGL Energy Ltd and an Adjunct Research Fellow at the University of New England. The authors are grateful for the insightful comments from Elizabeth Nosworthy on earlier drafts, and for the demographic study conducted by KPMG. The KPMG referenced information contained in this paper are extracts of a demographic analysis on hardship delivered Sep 2011 and do not necessarily represent the conclusive findings. The views and opinions contained in the article are those of the authors and do not necessarily represent the views AGL Energy Ltd or KPMG. All errors and omissions remain entirely the responsibility of the authors.

${ }^{1}$ See ABS at

http://www.abs.gov.au/AUSSTATS/abs@.nsf/allprimarymainfeatures/5475ABC397EA27DDCA257822001409A3?opendocument

${ }^{2}$ Based on AGL Energy consumer market data.
} 
of electricity tariff increases may also have helped households to focus on energy consumption. Simshauser and Laochumnanvanit (2012) found that press articles on energy prices increased in New South Wales from about 600 articles per annum in 2007 to more than 4250 articles in 2012, a 6.7-fold increase.

In contrast to the average household, rising electricity tariffs for the subset of customers defined as being 'in hardship' is considerably more serious than an episode of budgeting inconvenience. Simshauser, Nelson and Doan (2011a, 2011b) examined a scenario in which retail electricity tariffs would double between 2008 and 2015, and would in turn aggravate the incidence and severity of customer hardship. But, we also consider that there is the potential for a new problem not seen within the context of that article relating to recent declines in energy consumption.

The electricity transmission and distribution systems are regulated monopoly businesses with network tariffs based on a regulated return on the expected asset base during each five-year regulatory period. One implication of this is that if underlying energy growth rates decline (holding all other variables constant), network tariffs will be increased so that regulated returns are maintained. Falling underlying energy demand naturally results in higher tariffs, because the heavy fixed costs of the monopoly regulated networks are spread across fewer units of output.

Both underlying energy demand and peak demand contracted over the period between 2010 and 2012, the first such contraction in electricity demand on record in Australia. At the whole of power system level (i.e. transmission system), such contractions may persist in the short run. However, as Simshauser and Nelson (2013) explain, some localised distribution networks such as Southeast Queensland are forecasting (modest) positive growth in peak demand, and at rates higher than underlying energy demand. Hence over the longer run, there is at least the potential for a more dangerous scenario - rising peak demand and a simultaneous contraction in annual energy consumption. ${ }^{3}$ Under such a scenario, tariff increases to offset annual volumetric declines would be compounded by further tariff rises to meet returns on any incremental capital expenditure required to meet long run 'peak demand growth'. To be clear, it is network peak demand that is the primary driver of network expansion, not annual energy demand. It is not difficult to see how this could become a vicious cycle in the absence of careful intervention by policymakers, and in particular, the introduction of time-of-use and critical peak pricing structures.

In our view, it would be wise to avoid the introduction of inclining block or Clow Differential tariffs. As Houthakker (1951) explained more than 60 years ago, when faced with Clow Differential tariffs, consumers naturally economise at times least inconvenient to them. This is not during very hot critical peak weather events - the very events that drive additional investment. On the contrary, inclining block tariffs are likely to reduce capital utilisation by reducing non-critical event demand for energy. ${ }^{4}$

We have structured this article as follows; in Section 2, we outline the key pressures on electricity tariffs while in Section 3, we examine significant structural changes that have occurred in underlying energy demand as a result of global economic uncertainty. Section 4 then provides an overview of literature related to the energy market death spiral. Sections 5, 6 and 7 examine the concept of customer hardship in the energy sector and present detailed modelling of the incidence of hardship. Our policy recommendations and conclusions follow.

\footnotetext{
${ }^{3}$ At the distribution network element level, simultaneous increases in household peak demand and contractions in underlying energy demand could be driven by a higher uptake of Solar PV units. As QCA (2013) demonstrate, solar PV output (which has the effect of decreasing underlying energy demand) occurs during sunlight hours to $6 \mathrm{pm}$ whereas household peak demand occurs at 7:30pm. See in particular Figure 3.1 at page 13.

${ }^{4}$ AGL Energy Ltd had a seasonal inclining block tariff in the South Australian region of the NEM. AGL sought regulatory approval to abandon the structure from July 2013. The South Australian load factor has continued to decline year-on-year and has fallen from about 0.55 in the early 2000s to just 0.37 in 2011.
} 


\section{The momentum in the market for fuel and electricity system investments}

What is the retail price of electricity and what are the component charges? In very general terms, for our purposes current tariffs for households are about \$260/MWh in 2013, with power generation (including carbon pricing) accounting for about $27 \%$ of the costs, high and low voltage network costs comprising about $46 \%$, environmental schemes about $7 \%$ and retail supply costs about $11 \% .^{5}$

Historically, the cost of fuel used in power generation in Australia has been amongst the lowest in the world. Available domestic supply of thermal coal traditionally outstripped local demand, and as a result, Australia's thermal coal (i.e. coal used in electricity production) was contracted by way of very long-dated, fixed-price agreements to domestic power stations for less than $\$ 1.30 / \mathrm{GJ}$ or about \$30/t (see Simshauser, Nelson and Doan, 2011a). Transactions of this nature underpinned a rapid expansion of thermal power in Australia, in particular, throughout the late1970s, 1980s and early-1990s. By the mid-2000s, available natural gas was similarly in abundance relative to domestic demand and so long-dated, relatively low cost Gas Supply Agreements were common with pricing typically around \$3/GJ for unity load factor supplies (see Simshauser and Catt, 2012).

The outlook for fuel costs in the 2010's is different. Many domestic coal and gas producers are focused on creating the link between export markets and their output. The reason for this is aptly illustrated in Figure 1, which plots monthly Brent Crude (LHS axis, US\$/bbl), along with the spot prices for export coal, export LNG, and long-dated (i.e. historic) domestic coal and domestic gas contracts (RHS axis, measured in \$A/GJ) from 2000 to 2013.

Note in Figure 1 that existing long-dated contracts for Domestic Coal are priced at about $\$ 1.35 / G J$ by the end of the time series. In contrast, Export Coal (ex-Newcastle) is about $\$ 4.00 / G J$ by the end of the series, despite starting at the same unit price in 2000. Similarly, historic longdated gas contracts in Queensland struck at c.\$2.50/GJ as late as 2006 pale into insignificance by comparison to LNG ex-Japan, which is now trading above $\$ 15.00 / \mathrm{GJ}$, which after netting-back to the local well-head, equates to about $\$ 7.00 / G J$ using the parameters contained in Simshauser, Nelson and Doan (2011a). With the development of LNG export capabilities from the middle of the decade, domestic producers, to the extent that they reasonably can, can be expected to pursue export markets to maximise profits, and in turn, recoverable reserves (Nelson, 2012). The implication for domestic users of coal and gas is that they will face cost pressures given export prices available to suppliers, at least where those suppliers have genuine access to seaborne markets.

\footnotetext{
${ }^{5}$ These estimates and the components will vary considerably by region. Default tariffs in the NEM range from about $\$ 230$ $\$ 300 /$ MWh. Competitive discounts are then applied to these rates. The allocation of costs are based on AGL calculations and IPART (2012) for Sydney residents. 
Figure 1: $\quad$ Prices for raw fuel from 2000-2013

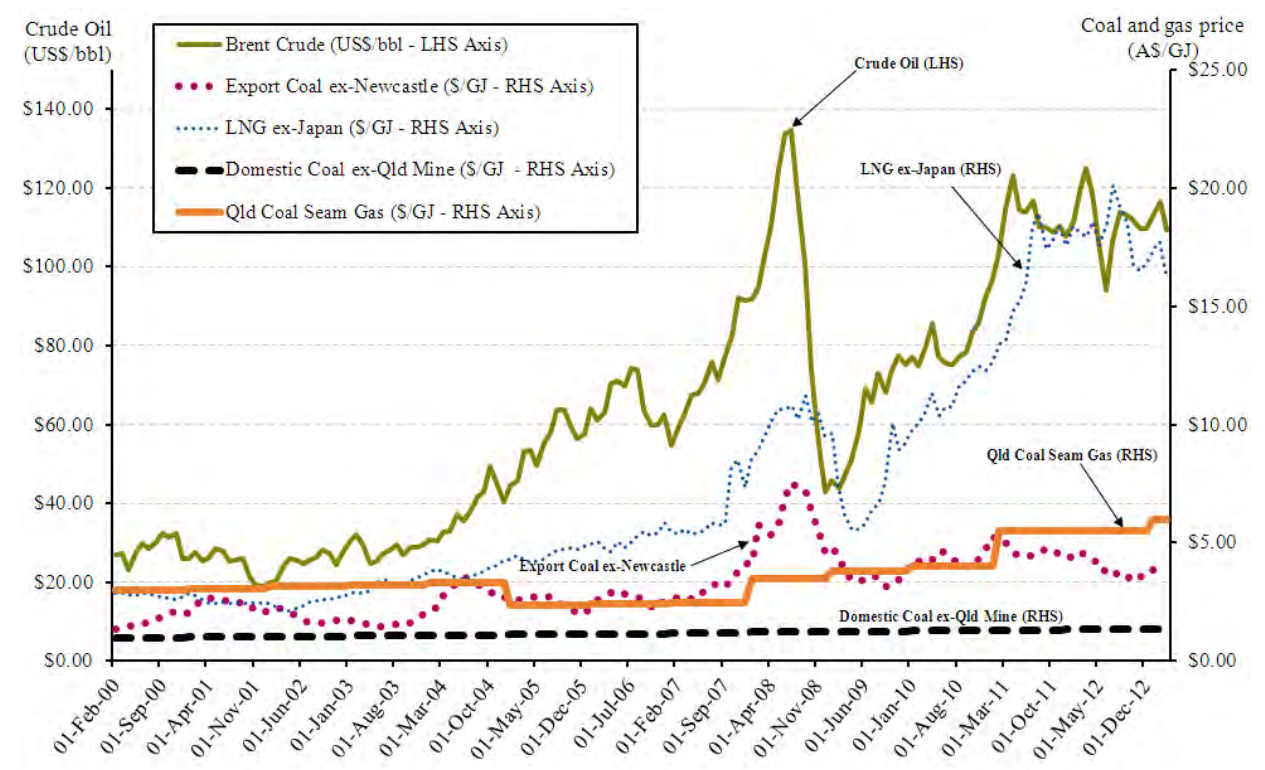

Source: Bloomberg, YCharts.

In the case of coal, the existence of export markets has not been of any great significance historically. On the one hand, domestic power plants accept substantially lesser quality thermal coal than that which is typically exported, while on the other hand, the price differential between the domestic and seaborne markets was rarely as substantial as now. The differential in local and seaborne coal prices can be traced back to 2003. We know of no other way to better capture momentum in global fuel markets than Figure 2, which combines demographic data on world population with annual oil, coal and gas production data. Note in particular the slowdown in oil production from 2003, and the consequent rapid rise in coal and gas production.

Figure 2: Global population and energy production

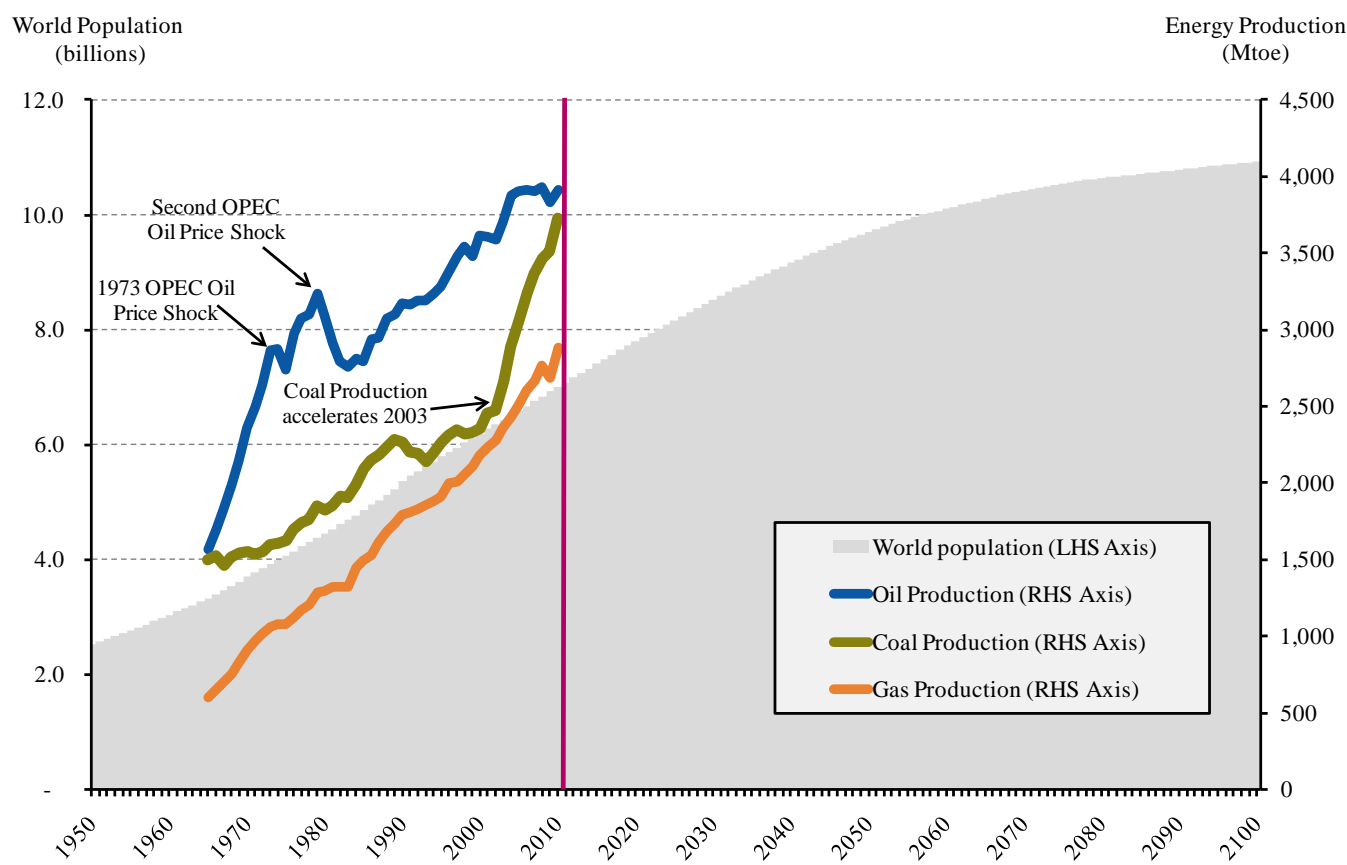

Sources: KPMG Demographics, BP Statistical Review (2012), UN (2011), AGL Energy Ltd. 
In analysing Figure 2, very long-range, trend-growth in total energy production (i.e. over a 40 year window) has averaged 2.0\% (year-on-year). The 10 -year period that exhibited the highest growth was the window leading up to the second OPEC oil price shock in 1978, where growth in global energy production was $4.2 \%$ pa. Growth in oil production was $6 \%+$ leading up to the first OPEC oil shock in 1973. However, following the second oil price shock in 1978 growth in oil production moderated to $1.3 \%$ pa and over the last 10 years has fallen to just $0.8 \%$ pa. This observation is important. Population growth is running at pace, and growth in oil production is grinding to a halt. As a result, coal and gas have been the high growth fuels.

Gas production has had a persistent long-range growth rate of $2.9 \%$ per annum, and recent nonconventional gas production levels (for example, shale gas in the US and coal seam gas in Australia) seem set to underscore this trend. But the most striking result in Figure 2 is the sharp run-up in coal production from 2003. Compound growth rates for coal output during the 2000s was $4.7 \%$, more than double the long-range average (2.3\%) and more than five times the growth in oil production.

From 2000-2010, global population increased by $13.0 \%$ while production of raw energy increased by $29.3 \%$. Since growth oil production has slowed, rising energy demand has been increasingly met by coal and gas (and indeed, renewables). In the 1980 s, oil accounted for $49.8 \%$ of the world's fossil energy mix but fell to just $37.2 \%$ by 2010 . Coal on the other hand has increased from $29.3 \%$ to $35.4 \%$, and gas has increased from $16.4 \%$ in the mid- 1960 s to $27.4 \%$ by $2010{ }^{6}$

The infrastructure requirements of China and other emerging economies are likely to place longrun pressure on key inputs to the electricity sector (i.e. metals, labour, capital and fuel). And in the case of fuel, over $90 \%$ of the NEM's electricity supply is currently derived from coal or gas. Historically, the unit cost of raw fuel has represented less than $10 \%$ of the average household electricity bill. The momentum gathering in fuel markets seems likely to change this with unit fuel costs quite capable of rising to more than $20 \%$ of the electricity bill in regions where fuel costs link to export markets. Introducing a price on carbon also had an impact. But rising fuel costs and the investment implications of environmental policies are not the only headwinds facing energy consumers in the NEM. As Simshauser and Catt (2012) recently noted, the annual investment in power generation, transmission and distribution networks was running at about \$11 billion pa from about 2007 through to 2011, substantially above long-term trend-growth of \$5 billion pa. This is illustrated in Figure 3.

\footnotetext{
${ }^{6}$ While not shown in Figure 2, more investment in electricity is now being directed into renewables than in coal and gas-fired generation. 
Figure 3: $\quad$ Energy Utilities Investment Megacycle - Investment in Plant 1955-2011

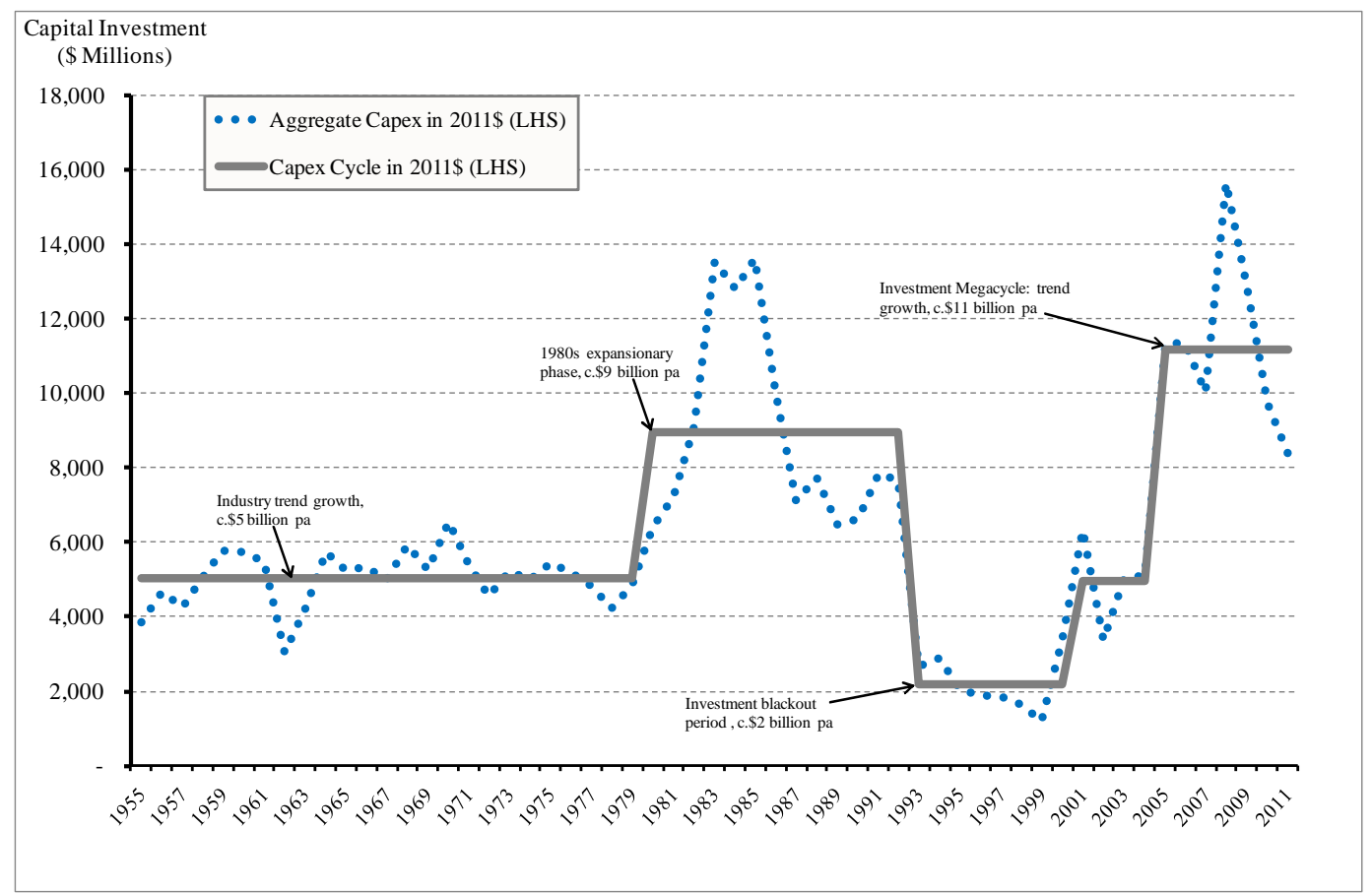

Source: Simshauser \& Catt (2012).

In Figure 3, aggregate annual investment in electricity system fixed assets is represented by the dotted line series, while a superimposed proximate 'industry investment cycle' - made possible by converting all capital expenditures into constant 2011 dollars - is given by the solid line. From Figure 3, note that investment between 1955 and 1979 was about $\$ 5$ billion pa. This occurred while electricity load growth was running at $7.9 \%$ pa. A run-up in investment to $\$ 9$ billion pa occurred during the 1980s, and along with it, commensurate electricity tariff increases. During this expansionary phase in the 1980s, load growth remained strong at 5.4\% pa. However, this high growth was lower than forecasts at the time. A series of discrete industrial loads (i.e. primarily aluminium smelters) was expected and in turn, drove the expansionary phase. But in the end, less than $50 \%$ of these new industrial electricity loads materialised (Kellow, 1996). Unsurprisingly, the electricity system was heavily oversupplied by the mid-1980s, and unit electricity price increases were higher than the industry, government and policymakers had anticipated. An "investment blackout" followed during the 1990s, in which aggregate industry investment fell to just $\$ 2$ billion pa. With continual growth in aggregate electricity demand, the oversupply eventually cleared and from 2000-2006 industry investment reverted to trend-growth of $\$ 5$ billion pa. The "investment megacycle” visibly commences from 2007 onwards.

There are broadly three drivers of the investment megacycle, two of which represent a broader global thematic. The first of these is asset replacement. Approximately one-third of the investment in network infrastructure in the NEM is currently being directed towards aged asset replacement. Like many advanced economies, Australia made substantial investments in electricity infrastructure in the 1970s and 1980s, and given the 30-50 year life of electricity equipment, portfolios require asset renewal. The second is the investment requirements associated with environmental policies such as renewable targets and greenhouse gas restrictions. Meeting Australia’s 20\% Renewable Energy Target (by 2020) is likely to require approximately $\$ 20-30$ billion worth of cumulative investments ${ }^{7}$. Electricity price increases are also prominent in Europe and the UK, and these two drivers, replacing aging assets and the investment implications of greenhouse gas and renewable energy targets are, again, common features.

\footnotetext{
${ }^{7}$ Further information on investment required under the policy is available in the final report of the Climate Change Authority's review of the RET (http://climatechangeauthority.gov.au/ret). A further review of the policy is required by legislation in 2014.
} 
But Australia has a third driver which seems to be less of a problem in Europe or the UK: a peak load problem. The issue for Australian energy consumers is that a non-trivial component of the investment megacycle, which notionally commenced in 2007, was initiated to meet the least efficient kind of demand growth - growth in peak demand, not base energy demand. When an investment megacycle combines with durably higher fuel prices and falling plant utilisation rates, it is not difficult to envisage substantial rises in electricity tariffs. In Simshauser, Nelson and Doan (2011a, 2011b), retail electricity tariffs were predicted to double in just seven years, between 2008 and 2015. To give this some historical context, it took 23 years, from 1985-2008, for electricity tariffs to double previously. Figure 4 is a reproduction of the work of Simshauser, Nelson and Doan (2011a, 2011b), along with the most recent changes in actual electricity tariffs in NSW.

Figure 4: $\quad$ NSW electricity tariffs from 1955-2015f

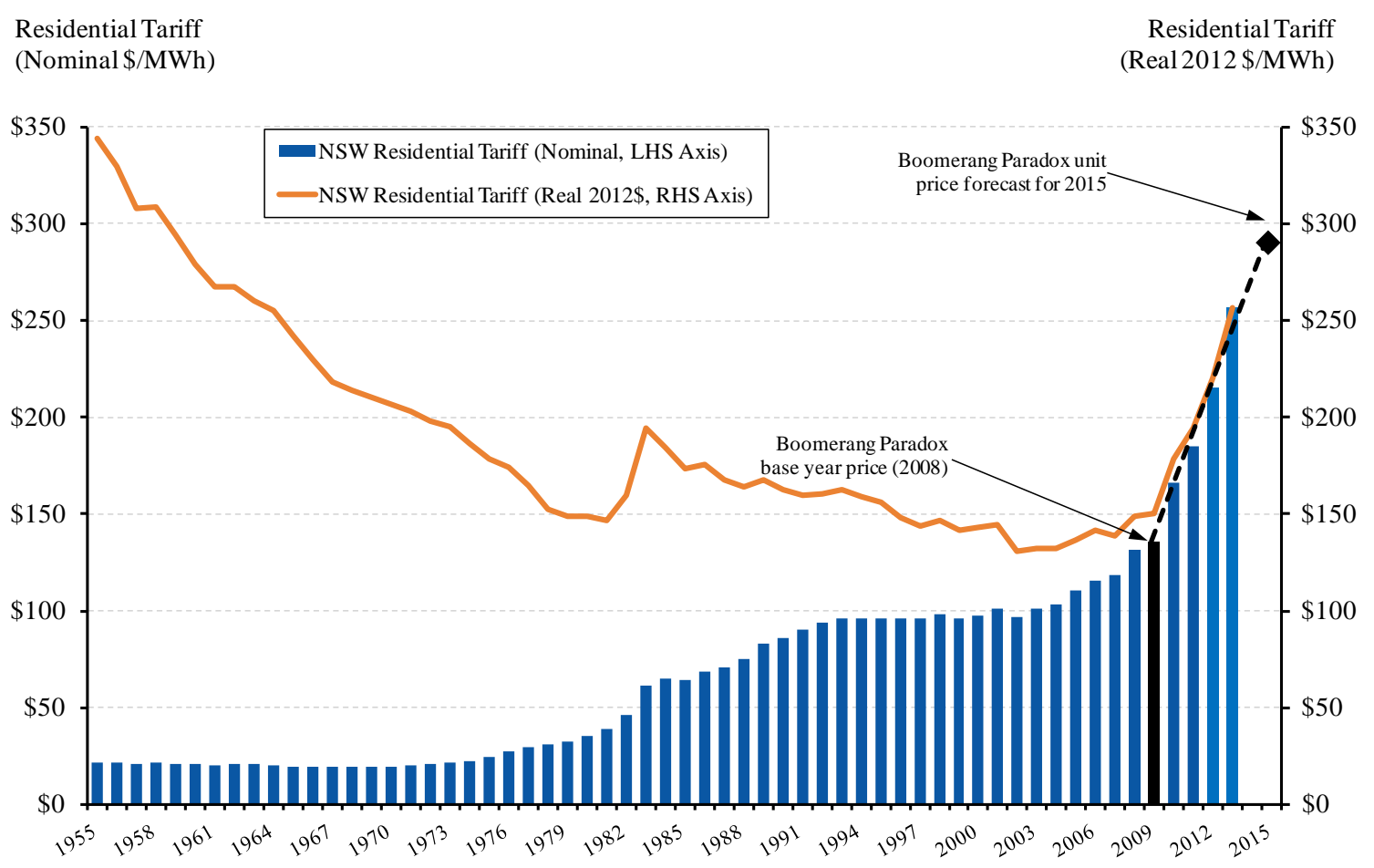

Source: Simshauser, Nelson and Doan (2011a, 2011b).

Large-scale investment in electricity equipment is not in and of itself a problem if it is intended to meet rising throughput. For example, while Kellow (1996) and Booth (2000) noted that the 1980s expansionary phase was excessive, growth in industrial energy demand and substantial household load growth via the arrival of cheap air conditioning units eventually utilised the productive capacity of the electricity system ${ }^{8}$. As a result, electricity tariffs "troughed" by the mid-2000s as Simshauser and Nelson (2013) explain.

\section{Economic growth and the momentum of energy demand}

Electricity demand forecasts are becoming more difficult to prepare due to the uncertain international economic environment and the changing expenditure patterns of households. As Figure 9 later highlights, macroeconomic conditions following the Global Financial Crisis produced Australia's first annual contraction in electricity production since World War II, from 2010.

\footnotetext{
${ }^{8}$ It should be noted that electricity market participants (including electricity retailers and network operators) actively sold air conditioning units through the 1990s and 2000s.
} 
The uncertain global economic conditions that exist at the time of writing are likely to persist for some time to come. Reinhart and Rogoff (2009), and the IMF (2009, p.112, 119), examined the short run output dynamics of 122 recessions over the last 50 years from 21 developed economies and noted that:

...recessions associated with financial crises have typically been severe and protracted, and recoveries have been slower, held back by weak private demand and credit. In addition, highly synchronized recession episodes [defined as recessions simultaneously impacting 10 of the 21 advanced economies] are longer and deeper than other recessions. Moreover, developments in the United States often play a pivotal role both in the severity and duration of highly synchronized recessions... Recessions that are associated with both financial crises and synchronized global downturns have been unusually severe and long lasting. Since 1960, there have only been 6 recessions out of 122 that fit this description...

The Global Financial Crisis of 2008-09, otherwise known as The Great Recession (Stiglitz, 2010), fits this definition as it was both precipitated by a financial crisis and was globally synchronised. Such conditions in less acute downturns typically lasted for seven quarters from peak to trough, in which GDP falls by $4.8 \%$. The subsequent economic recovery runs at only half this rate, meaning that an economy hit by such downturns will virtually stand still for at least four years. Within Australia, non-resource sectors have deteriorated, and face the real prospect of an equivalent episode of at least four years of stagnation. Much of this is driven by a combination of consumer caution and reduced credit as households and firms deleverage their balance sheets. As the IMF (2009, pp 116-117) observed in relation to the international economy:

What do these observations tell us about the dynamics of recovery after a financial crisis? Households and firms either perceive a stronger need to restore their balance sheets after a period of over-leveraging, or are constrained to do so by sharp reductions in credit supply. Private consumption growth is likely to be weak until households are comfortable that they are more financially secure. It would be a mistake to think of recovery from such episodes as a process in which an economy simply reverts to its previous state.

In Australia, households are evidently restoring balance sheets as a result of perceptions of being over-leveraged just as the IMF predicted in 2009. It is possible, in our opinion, that such activities may drive reductions in household energy demand growth but may not be as effective in reducing temperature driven peak demand.

(a) Savings: As Figure 5 illustrates, the average savings rate of Australian households from 2000-2008 was just 1\%. Rising real property values and innovations in banking allowed consumers to convert their previously illiquid housing stock into available funds via redraw facilities, thus driving consumer spending to record levels (Reinhart and Rogoff, 2009). But since the collapse of Lehman Brothers in 2008, household savings rates in Australia have increased to about 11\%, a level not seen in Australia since just prior to the stock crash of 1987. BCG (2011) noted in their international survey of consumer spending plans that Australians are amongst the most cautious, despite living in one of the best performing economies in the world. Surprisingly, BCG (2011) found that Australian consumer spending plans differed little from consumers in crisis-ridden Greece, and other economies under duress such Italy and the United Kingdom. 
Figure 5: $\quad$ Australian household savings rates 1960-2013

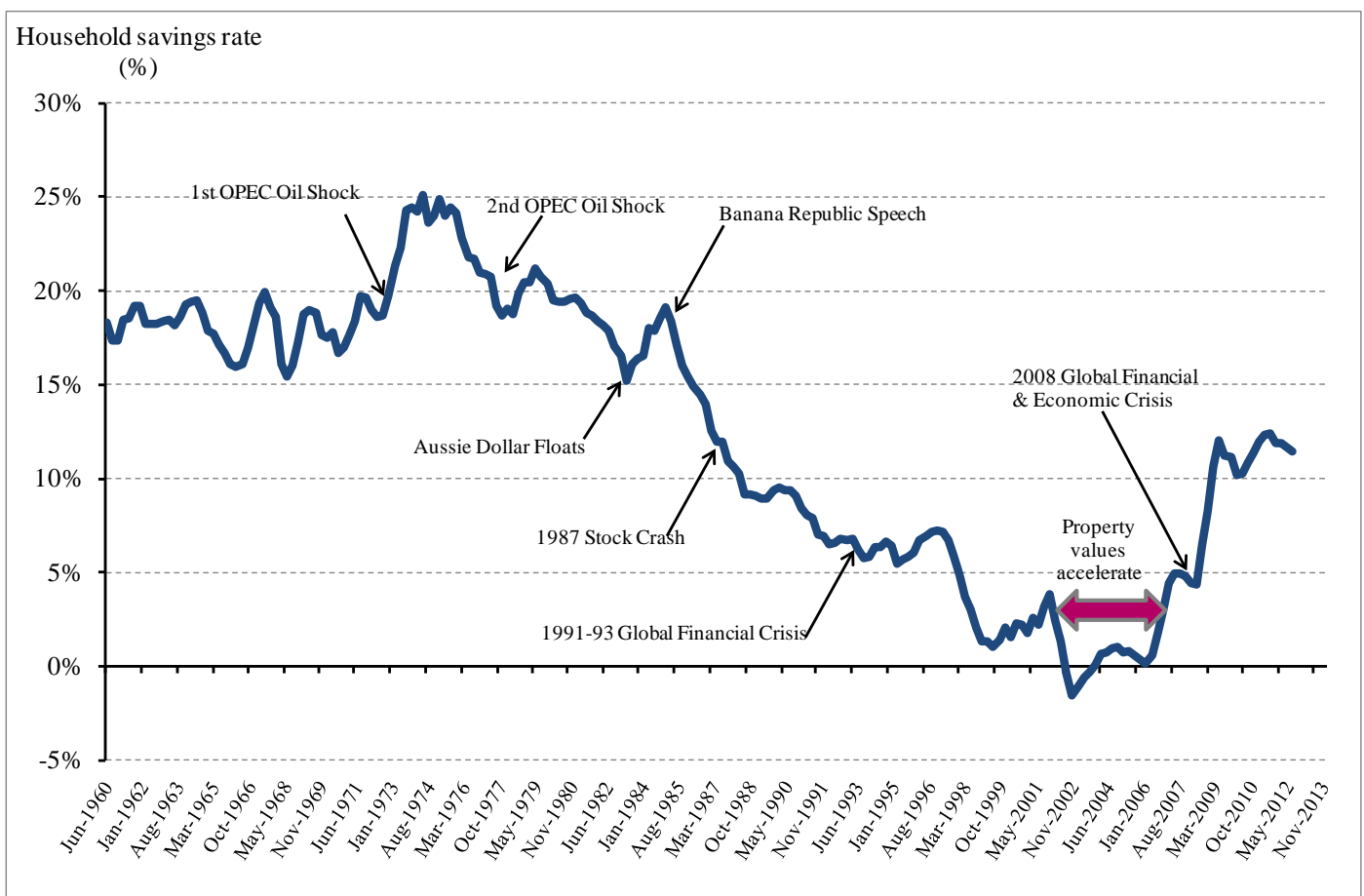

Source: RBA, AGL Energy Ltd.

(b) Credit: A large component of economic growth is driven by consumer spending, and a large component of growth in consumer spending is fuelled by the availability of bank credit. Credit is, therefore, an important growth catalyst and a lead indicator for nonmining sectors. But Australian credit markets reveal constrained trends, as Figure 6 highlights. Whereas the use of personal credit increased by $43 \%$ during the four years leading up to the Great Recession, over the following four years it contracted by $18.3 \%$. Similarly, business credit expanded by $64.5 \%$ pa over the four years leading up to the Great Recession, but has since fallen by $12.5 \%$. All things being equal, if credit is rationed in its supply or use in comparative terms, economic growth will be sub-par. Figure 6 illustrates aggregate business credit and personal credit. 
Figure 6: $\quad$ Growth in Australian Business and Personal Credit - 1990-2013

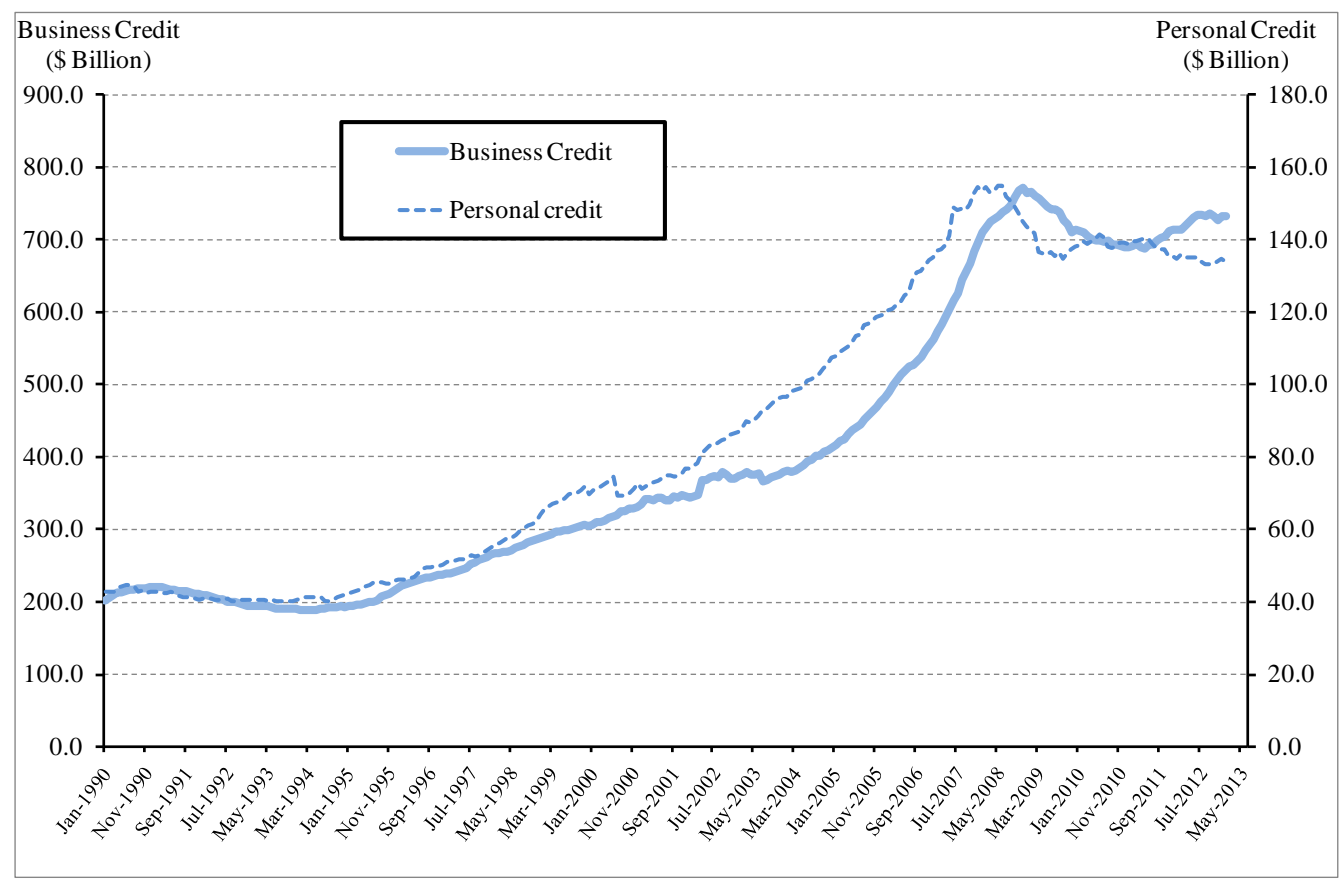

Source: RBA, AGL Energy Ltd.

The changing patterns in household savings, credit markets and consumer spending (i.e. absolute level and identifiable changes in the composition of goods and services) will inevitably have an impact on energy demand. While the short run drivers of energy demand are anthropogenic patterns and weather conditions, at the household level, long run demand can be broken into three separate drivers: ${ }^{9}$

- Structural effect: this component of energy demand is driven by population growth and the number of new household (and business) connections, and more recently, has been offset by government policies aimed at reducing negative externalities associated with climate change. This has historically contributed about 1.8 percentage points to demand growth, but since the Great Recession has fallen to 1.2\%. Population growth has slowed to $1.7 \%$ (down from $2.2 \%$ in 2008), ${ }^{10}$ while new housing approvals in 2012 had fallen by $15.2 \%$ compared to 2011, and remain substantially below the approval levels of $2007 .{ }^{11}$ Greenhouse gas emissions have also been falling in line with climate change-related policy changes.

- Cyclical effect: this component of demand is driven by the composition of households. Growth in average dwelling floor space has been material, increasing from 113 square metres in 1990 to about 150 square metres in 2011, with the incremental housing stock at 245 meters. Growth in the number of appliances within the household such as airconditioning, clothes dryers, and the extent of discretionary goods such as computing equipment, flat screen televisions and set-top boxes has also been important, with the average household stock increasing from 46 appliances in 2000 to 67 appliances in 2010, with an average of 38 appliances plugged-in, and 25 appliances at anytime using standby power (Phillips, 2012). Historically this has contributed about 1.2 percentage points to demand growth, but since the Great Recession appears to have stalled.

\footnotetext{
${ }^{9}$ We acknowledge the work of ABARE (2010) who first described three drivers of demand. Our concepts are similar, but not identical, to ABARE's (2010) research.

${ }^{10}$ See http://www.abs.gov.au/ausstats/abs@.nsf/mf/3101.0 for details.

${ }^{11}$ See http://www.abs.gov.au/AUSSTATS/abs@.nsf/DetailsPage/8731.0February\%202012?OpenDocument for details.
} 
- Productivity effect: this component relates to reductions in demand related to improvements in the energy efficiency of appliances, and the quality of materials used in the housing stock and on average, is thought to be $-0.9 \%$ per year.

Of course, household energy consumption comprises only one third of total electricity system demand (albeit noting that households comprise about $60 \%$ of the peak load in metro areas and $80 \%$ of the assets deployed ${ }^{12}$ ), and so in aggregate the long run driver of energy is nation-wide economic growth. Figure 7 presents Australian annual economic growth rates and NEM generation growth rates (using a 3 year moving average) over the 51 year period from 1960 to 2011.

Figure 7: GDP growth rate vs. NEM electricity production growth rate - 1960-2012

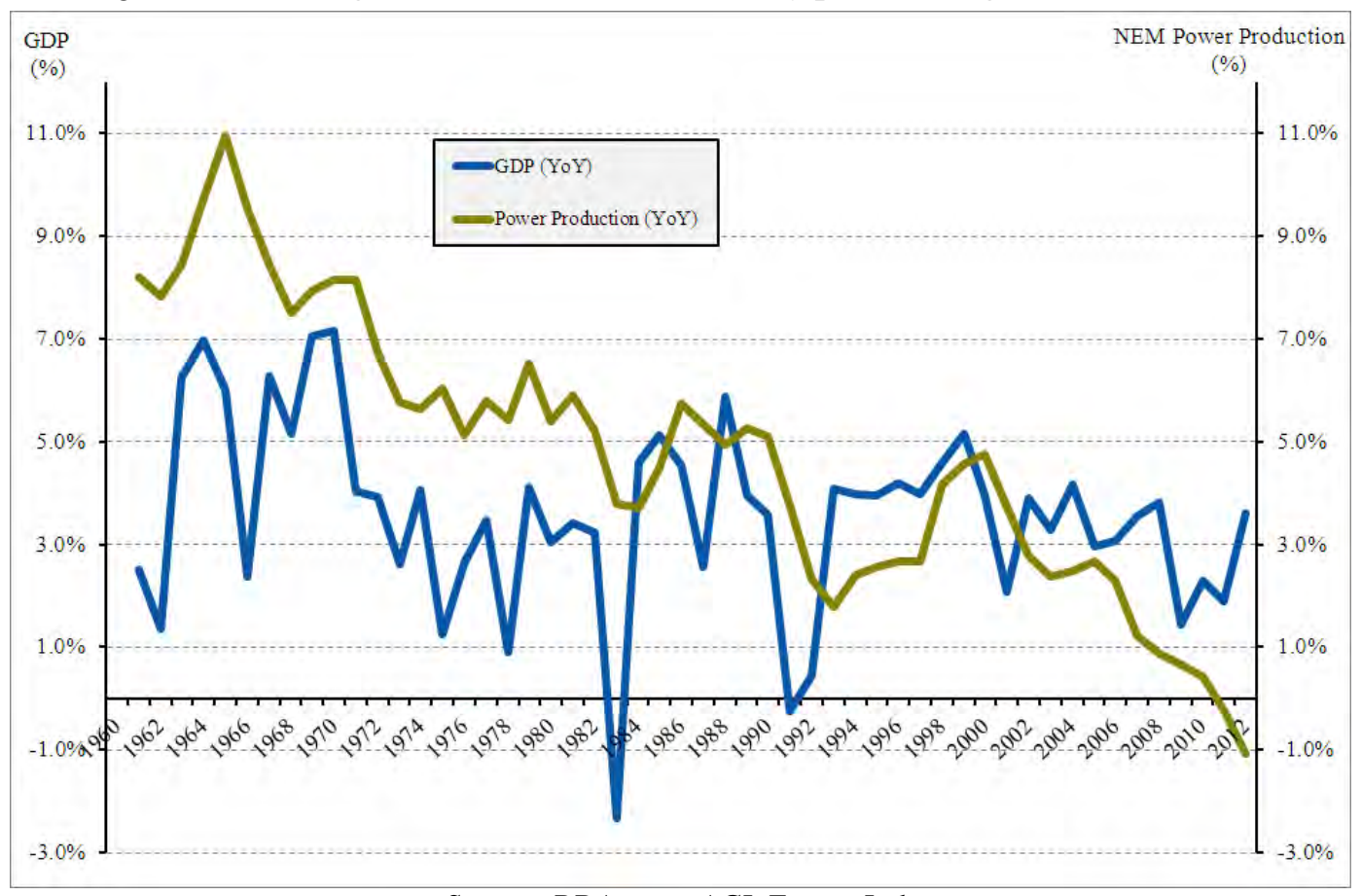

Source: RBA, esaa, AGL Energy Ltd.

Economic growth for Australia has averaged 3.6\%, with electricity production averaging 5.0\% some 1.3 percentage points higher than GDP. Of course, these are extremely long run averages. When analysed over the past 10 years, economic growth has averaged about $3.0 \%$ whereas electricity production has fallen below GDP, to just $0.8 \%$ or less than a third of trend GDP. Often it is the case that as an economy matures, a point occurs in which energy production decelerates below trend economic growth. It is entirely possible (based upon examination of Figure 7) that further reductions in energy demand may occur in the future.

Figure 8 presents cumulative Australian economic growth and electricity production from 1960 on the LHS y-axis expressed as an index, the differential rate of growth of electricity production (i.e. electricity production less economic growth) and an associated trend-line as measured by the RHS y-axis. The growth differential trend-line captures the essence of the issue. Notice that from the mid-1990s, the trend line drops below 0\% on the RHS y-axis, meaning that from the mid-1990s, electricity production growth rates fell below Australia's GDP growth rates - the growth disconnect had essentially been confirmed.

\footnotetext{
${ }^{12}$ For details of the asset allocation, see Energex (2012).
} 
Figure 8: Cumulative GDP growth vs. NEM energy production growth - 1960-2011

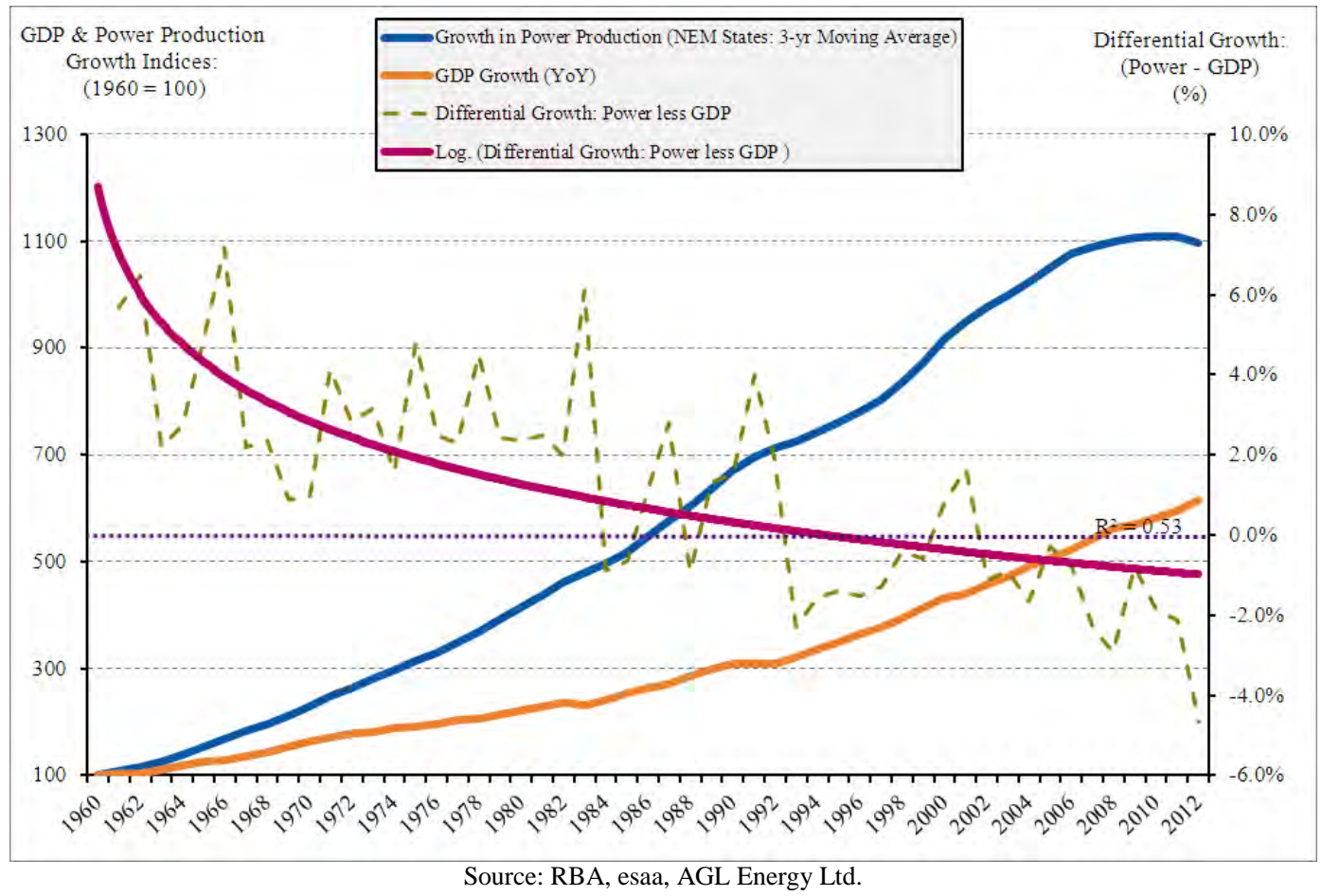

Yet, electricity production is not just decelerating below trend economic growth - production levels are currently contracting. While this is indeed most unusual by Australian standards, it is not atypical after severe economic shocks. Figure 9 plots annual electricity production in Terrawatt Hours (TWh) for the NEM (to 2012, RHS y-axis) and contrasts this with a electricity production index series for the USA, UK, France, Japan and Germany from 1990-2011 (LHS yaxis). Notice that electricity production experienced a sharp slump during the Great Recession in all economies. The British pool reduced by almost 8\%, from 398TWh in 2005 to just 365TWh in 2011.

Figure 9: Stalling electricity production: 1990-2012

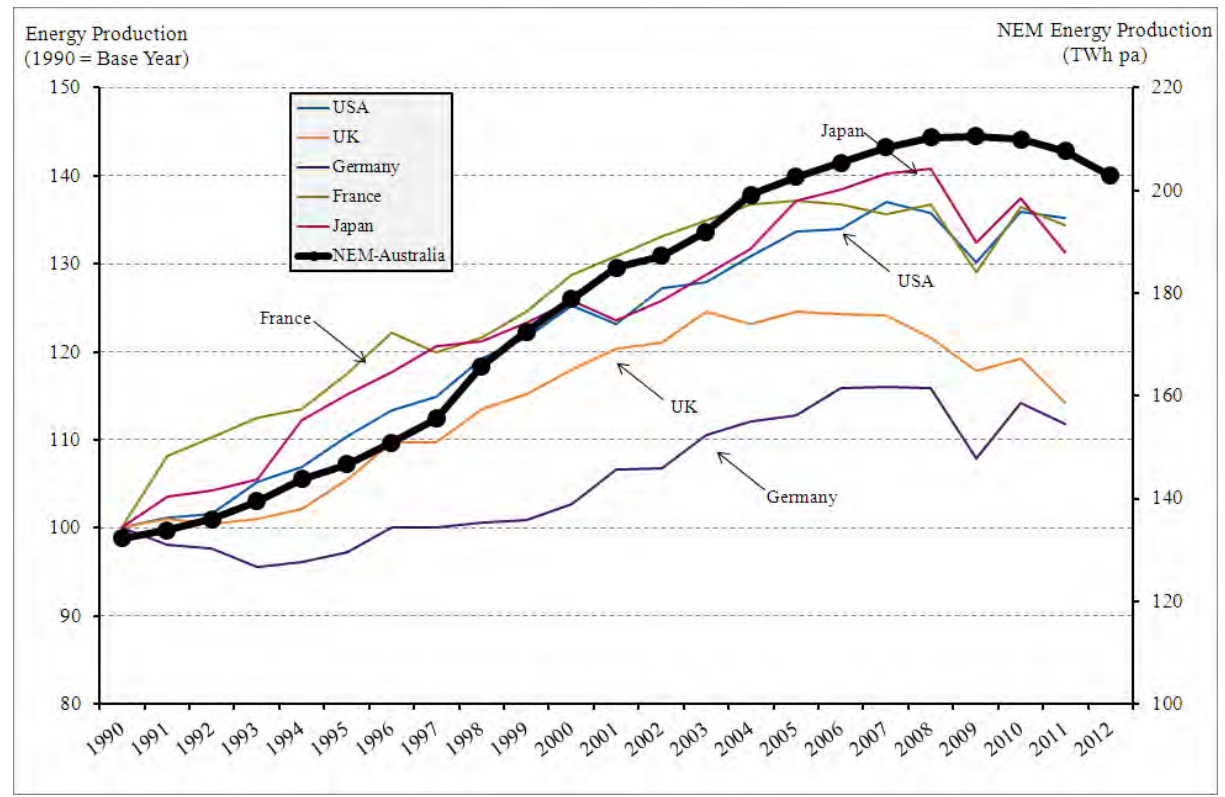

Source: AGL Energy, ESAA, BP Statistical Review. 
Forecast growth rates for NEM energy demand are now being revised downwards by central forecasting agencies, albeit noting that peak demand forecasts continue to meet or exceed underlying energy demand forecasts particularly at the distribution network element level as Simshauser and Nelson (2013) note.

\section{An Energy market death spiral?}

Growth in peak demand from 2005 to 2010 is responsible for a large proportion of the investment megacycle highlighted in Figure 3. The AEMC (2011) noted that for much of the 2000s, peak demand growth was running at twice the growth rate of underlying energy demand. ${ }^{13}$ We noted earlier that the transmission and distribution network tariffs (which form almost half of the headline electricity price) are regulated according to the size of the asset base, and if consumption declines, tariffs will ultimately be reset to ensure regulated returns are met. We also noted earlier that demand contracted between 2010-2012. This trend may well persist over the short- to medium-term. Indeed, our own internal load data associated with AGL Energy's 3.5 million accounts reveals that household underlying energy demand has declined by $6 \%$ over the past two years although manufacturing loads, which in our view had a special role in the reductions in underlying energy demand in 2010-2012, appear to have stabilised - notwithstanding a series of more recent manufacturing plant closures. ${ }^{14}$ Over the medium- to longer-term, AEMO (2012) is projecting peak demand growth of 1.0-1.6\% in New South Wales, Victoria and South Australia, and 2.5\% per annum in Queensland. Critically, AEMO (2012) is forecasting a faster peak demand growth rate in three of the NEM's five jurisdictions (i.e. Victoria, South Australia and Tasmania) which would have the effect of further reducing capacity utilisation. Simshauser and Nelson (2013) highlighted that NEM-wide generation plant capacity utilisation has already fallen from 58\% in 2007 to around 50\% at present. Further deteriorations associated with network plant should be of concern to policymakers. The salient point here is that over the longer run, unless the utilisation of energy assets and particularly network assets improve, given current regulatory arrangements, tariffs would be increased to compensate network owners for their sunk investments. ${ }^{15}$ From a policy and energy utilities perspective, the most troubling aspect of such momentum is that an energy market death spiral has at least the potential to manifest. This concept was defined by Severance (2011, p13):

The unspoken fear of all utility managers is the "Death Spiral Scenario". In this nightmare, a utility commits to build new equipment. However, when electric rates are raised to pay for the new plant, the rate shock moves customers to cut their $k W h$ use. The utility then raises its rates even higher - causing a further spiral as customers cut their use even more... In the final stages of that death spiral, the more affluent customers drastically cut purchases by implementing efficiency and on-site [solar PV] power, but the poorest customers have been unable to finance such measures...

The two variables identified by Severance (2011) are compounding. If underlying energy demand decreases, tariffs must rise above traditional run-rates to offset volumetric losses. And increases in peak demand manifest themselves in higher capital expenditure in network assets

\footnotetext{
${ }^{13}$ A reviewer of this manuscript made the salient observation that peak demand declined in all jurisdictions in 2011. However, summer temperatures were cooler than in previous years. AEMO, as the market operator, continues to forecast that peak energy demand growth will outstrip underlying energy demand in multiple regions.

${ }^{14}$ An analysis of AGL Energy's customers showed that contraction in industrial and commercial loads, which began to emerge following the Great Recession, appeared to have largely stabilised over the past two years to 2013. However, IES (2013) noted that in New South Wales, BlueScope Steel mothballed its No.6 blast furnace at Port Kembla in 2011, and in 2012, Shell closed their Clyde Refinery, Heinz closed their Wagga Wagga factory, Cement Australia closed their Kandos cement plant, Reckitt Benckinser closed their West Ryde plant and Orica's Kooragang plant experienced material disruptions to production. More significant to electricity load was the closure of the Kurri Kurri aluminium smelter in 2012. The electricity load associated with the aluminium smelter represented 3\% of aggregate demand in New South Wales. A key driver of these closures has been driven the high Australian dollar.

${ }^{15}$ We expect network tariffs to decline in the next 5-year regulatory reset periods due to a reduction in the allowable economic return (i.e. weighted average cost of capital). This is likely to occur regardless of whether load factors improve or deteriorate. Regardless, growth in peak demand should remain a focus of policymakers to ensure that asset utilisation rates improve to avoid unnecessary increases in future network tariffs.
} 
(and generation plant) to maintain security of supply given the inability to store electricity, leading to a further round of tariff rises. ${ }^{16}$ There are also indirect costs associated with rising peak demand. Peak load is most efficiently serviced by deploying open-cycle gas turbines, which have emissions intensities of around 0.7 tonnes per MWh. As such, the costs of meeting peak demand should also include either the costs of mitigation (i.e. a carbon price) or adaptation (costs associated with anthropogenic climate change). It is these characteristics, when combined with asset replacement and environmentally-driven investments that has at least the potential to drive an energy market death spiral scenario in the absence of policy intervention. ${ }^{17}$

But declines in energy demand from 2010 to 2012 make such a scenario highly unlikely in the short run. In a static sense, given recent declines in both energy demand and peak demand, some component of the investment megacycle may represent what Boiteux (1961) described as 'overequipment' - at least in the short- to medium-term. And as one reviewer rightly noted, firms should not expect to receive economic returns on excess investment. In the wholesale market, intense competition and the real-time uniform first-price auction clearing mechanism generally results in economic returns are inversely correlated with supply imbalances. However, this is not currently the case with regulated monopoly network assets - network tariffs are based on prevailing assets and the regulated economic return. Policymakers would need to change the National Electricity Rules for a regulator to "strand" investments that are subsequently proven to be surplus to requirement. If contractions in peak demand prove to be more enduring, such changes to the Rules will invariably, and appropriately, come into sharp focus.

\section{Customers in hardship}

Simshauser, Nelson and Doan (2011a, 2011b) noted that for the majority of households electricity tariff increases will be more of a household budgeting inconvenience than anything else. The most recent ABS Household Survey revealed that energy bills are no more significant now than in 2003/04 at the time of the last survey because household incomes have also been rising rapidly and individual household use has declined. That energy bills have remained at $2.6 \%$ of the average household budget underscores the notion that customer hardship is not a substantive problem per se. This is of course of little consolation to the subset of households in hardship. To put this issue into context, Figure 10 maps out the NEM population, the number of residential electricity and gas connections, and from AGL's databases, the credit characteristics of our 2.4 million households (representing 3.5 million electricity and gas accounts). AGL data represents about $1 / 4$ of all households, which we assume to be adequately representative of the NEM.

\footnotetext{
16 There are also indirect costs associated with the death spiral concept. Peak demand is increasingly met utilising open-cycle turbines which have emissions intensities of around 0.7 tonnes per MWh. As such, the costs of meeting peak demand should also include either the costs of mitigation (i.e. a carbon price of some sort) or adaptation (costs associated with anthropogenic climate change).

${ }^{17}$ Based on historical experience, a death spiral is more than a theoretical possibility. During 2010 in NSW for example, the annual energy consumption of households fell by 3.7\% while simultaneously, network companies invested $\$ 3$ billion into the grid to cope with rising peak demand (esaa 2010; Simshauser, Nelson and Doan, 2011a).
} 
Figure 10: AGL Customer base, credit behaviour and "Staying Connected"

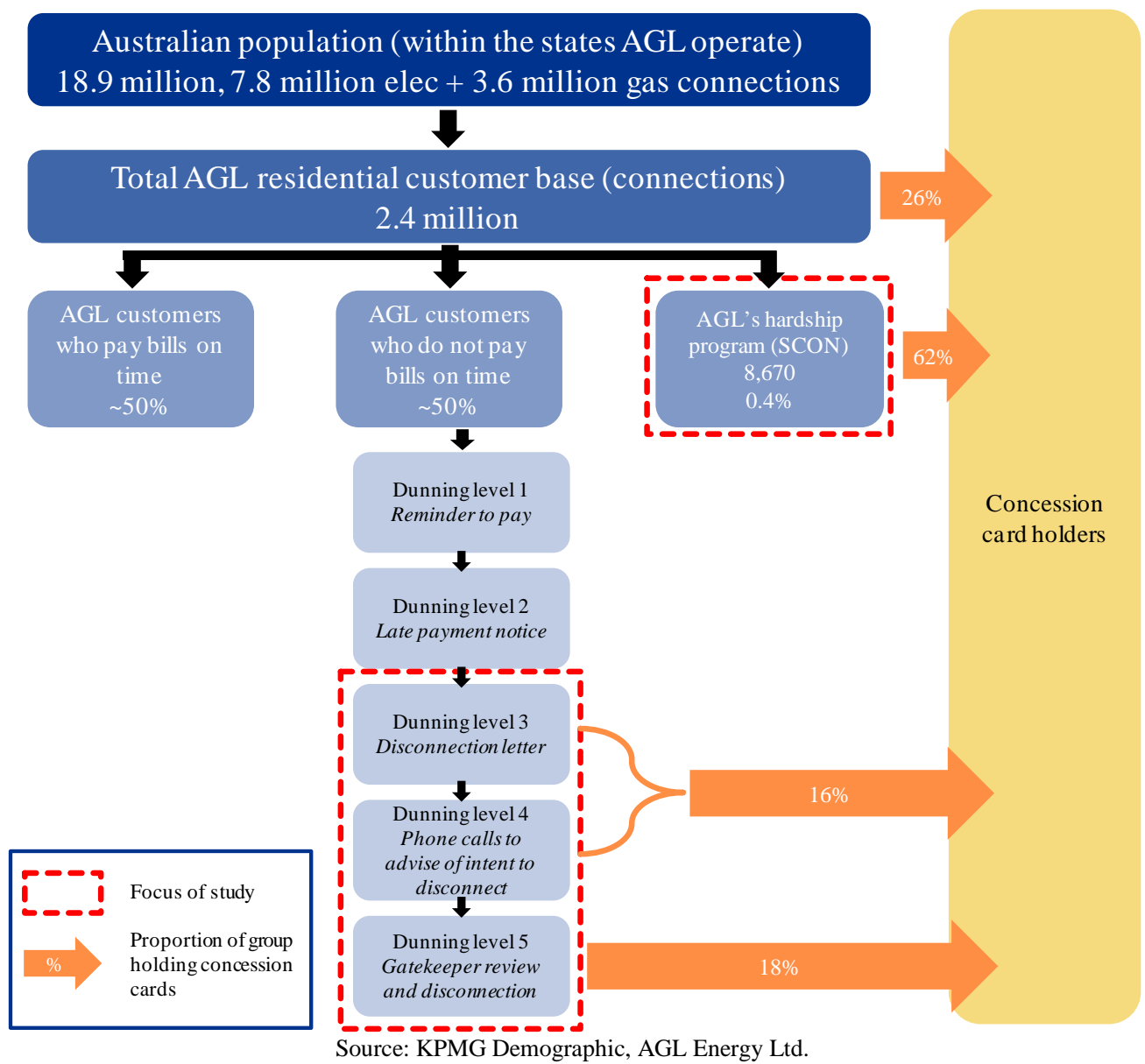

Note from Figure 10 that approximately only 50\% of customers pay on time, and thus half of the customer base utilise their energy retailer as a source of almost costless short term credit. The subset of customers who are on AGL's hardship program (i.e. "Staying Connected”) represents only $0.4 \%$ of the customer base. Figure 10 also highlights that $26 \%$ of AGL connected households have a concession card.

\section{Disconnection of households}

When a customer has difficulty paying their energy bill, are they disconnected? The short answer is no - so long as they remain engaged with their energy retailer. Energy Retailers do not purposefully disconnect a residential customer just because they cannot afford to pay their electricity or gas bill, given the essential service nature of these commodities. The distinguishing feature here is the underlying credit behaviour of the customer. Where customers have the willingness, but not the ability to pay, and in the event remain engaged with the firm then the customer is placed into a hardship program (such as the AGL Staying Connected program). The customer is then provided with access to a combination of in-home energy audits by AGL technicians, bill smoothing and bill payment re-scheduling, access to financial counselling and an analysis of potential assistance sources typically available to the customer in hardship from government and non-government sources. 
Figure 10 also sets out the high-level process followed once a customer account falls into arrears and enters the 'Dunning” process ${ }^{18}$. Initially, an SMS reminder is sent followed by direct phone call, then a written late notice (known as 'Dunning Level 2') which is followed by a written notice of intent to disconnect (known as 'Dunning Level 3'), followed by a further phone call confirming the intent to disconnect (known as 'Dunning Level 4'). At this point, an internal 'gatekeeper review' is undertaken to confirm all efforts to engage with the customer have been exhausted (known as 'Dunning Level 5'). Disconnection therefore only occurs when a customer has "disengaged" with their Energy Retailer.

Customer credit behaviour is currently polarised. Recent experience with AGL's 2.4 million household customers and the 3.5 million energy accounts (i.e. some households purchase both electricity and gas) indicates that customer payment speed largely reflects inverse movements to broader measures of consumer sentiment, perhaps counter-intuitively. As consumer sentiment declined, those customers paying on time paid faster than ever before, reflecting the strong desire of households to restore balance sheets, and to bring their finances under control. This increased speed of payment, particularly during 2009 and 2010, is illustrated in Figure 11. Our Payment Speed Index (Year-on-Year change) - constructed specifically for this article - is based on an underlying analysis of 'sales days outstanding' that removes the impact of unit price variations that typically plagues an analysis of accounts receivable data in a rising cost environment. Notice that the Payment Speed Index appears to be leading the Year-on-Year change in one of the Australian economy's principle leading indicators, the WMI Consumer Sentiment Index - which is also included in Figure 11 but lagged by four months. We have also layered in the Year-onYear change in official interest rates (RHS axis, reverse scale).

Figure 11: $\quad$ Payment Speed vs. Consumer Sentiment (YoY change, 2009-2013)

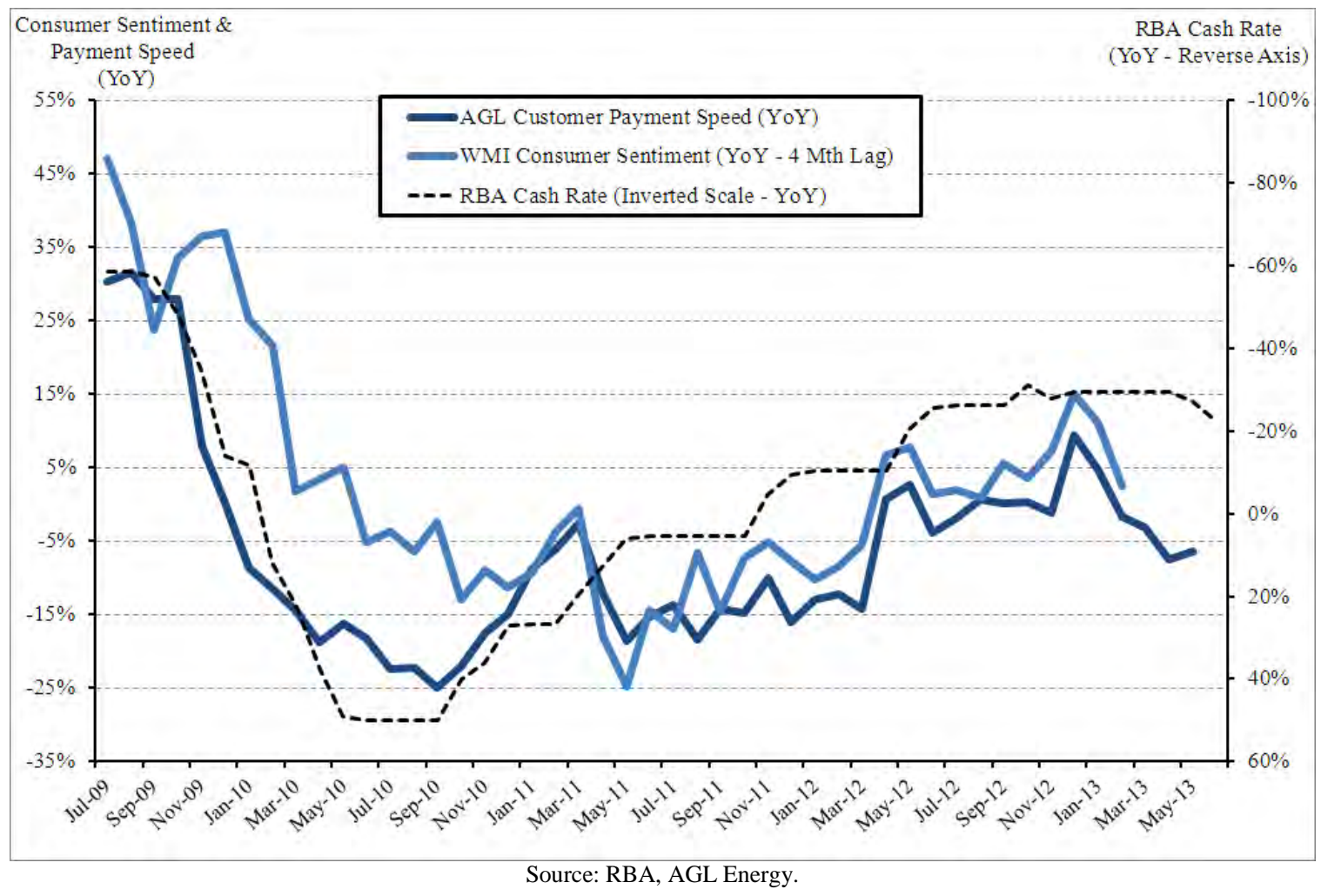

The polarisation of credit behaviour means that while some households were increasing their Payment Speed, at the other end, disconnection rates were rising during the episode of falling

\footnotetext{
${ }^{18}$ The "Dunning" process refers to the system used by electricity retailers to progressively escalate the process and form of notification to a customer that has failed to meet a scheduled payment.
} 
Consumer Sentiment from 2009 to 2011. This underscores the notion that the historical tactical responses by jurisdictional governments is not dealing to the core of the issue. This is as much a macroeconomic issue as it is an energy sector issue. Figure 12 illustrates Annual Household Disconnection Rates on the LHS y-axis and the WMI Consumer Sentiment Index on the RHS yaxis, although on this occasion with a reverse scale (i.e. as the line series rises, consumer sentiment is falling). We have also included an adjusted disconnection rate, which accounts for a structural break in disconnections associated with a change in technology. ${ }^{19}$

Figure 12: Household disconnection rates and consumer sentiment ${ }^{20}$

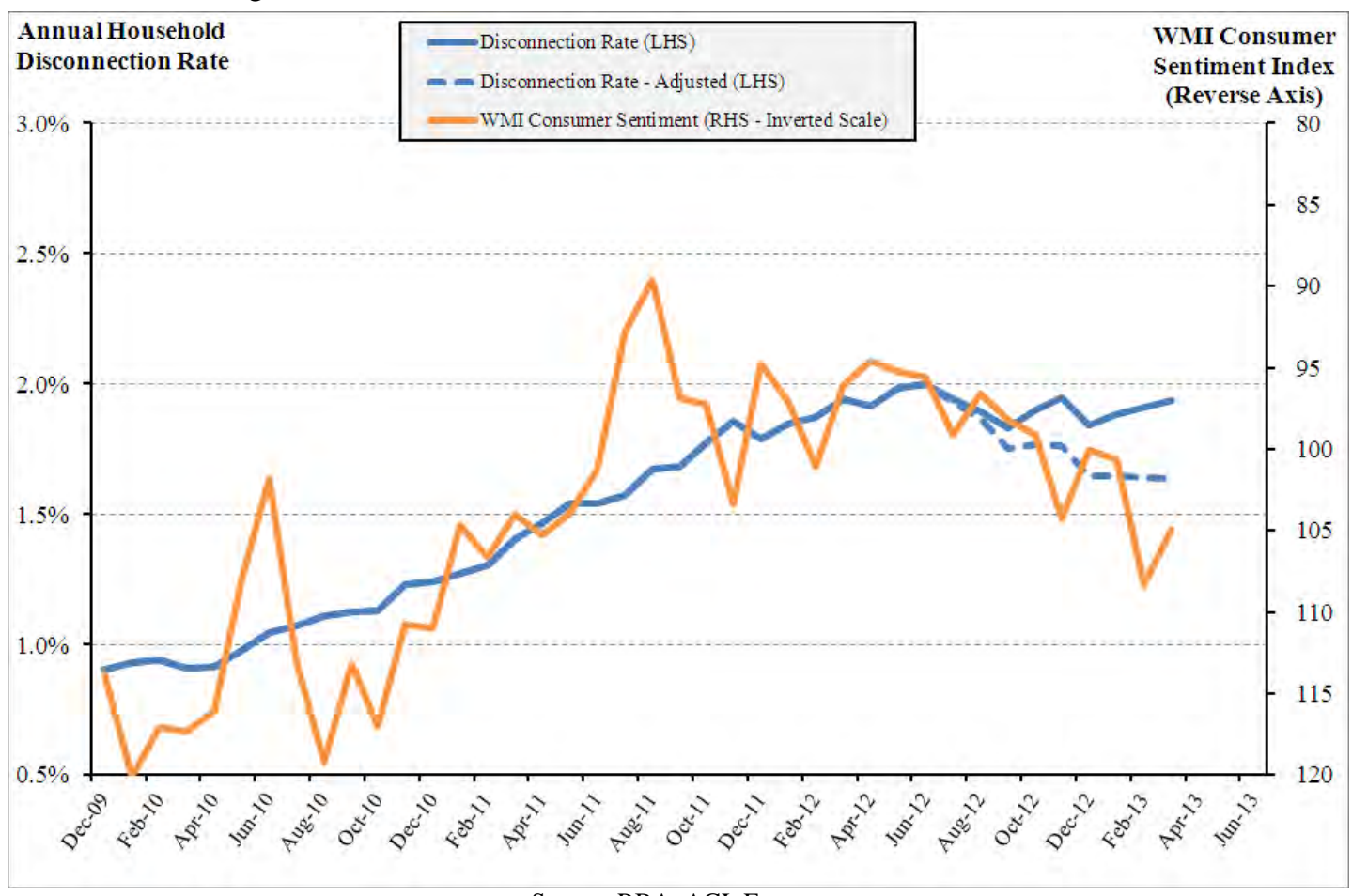

Source: RBA, AGL Energy.

Our concerns here are twofold. During episodes of declining consumer sentiment, Payment Speed increases at one end of the spectrum of all consumers, and Disconnection Rates rise at the other (with correlations in excess of 0.80 ). While there may be short-term structural components to disconnection rates, the macroeconomic conditions associated with the two-speed economy are more likely the dominant driver of favourable Payment Speeds and unfavourable Disconnection Rate movements. This may change as the current structural abnormalities of the Australian economy (e.g. high \$A) no longer apply.

\section{The incidence of hardship in the NEM}

We commissioned KPMG to undertake a demographic study on hardship which helped us combine AGL's 2.4 million household accounts data with ABS census data. Through the ensuing analysis we concluded that the primacy of hardship is in fact a subset of the Family Formation cohort (households where the primary account holder is aged between 30 and 49). This is illustrated in Figures 13-16. The results are representative of a data set comprising more than 13 million energy accounts issued in a single year.

\footnotetext{
${ }^{19}$ Smart meter technology allows for remote energisation and de-energisation. Accordingly, this increases the absolute speed of connection rates in either direction.

${ }^{20}$ Consumer sentiment is plotted on an inverse axis to clearly demonstrated the inverse correlation between disconnections and consumer confidence.
} 
Figure 13: Age distribution of AGL's 2.4 million customers and the incidence of hardship

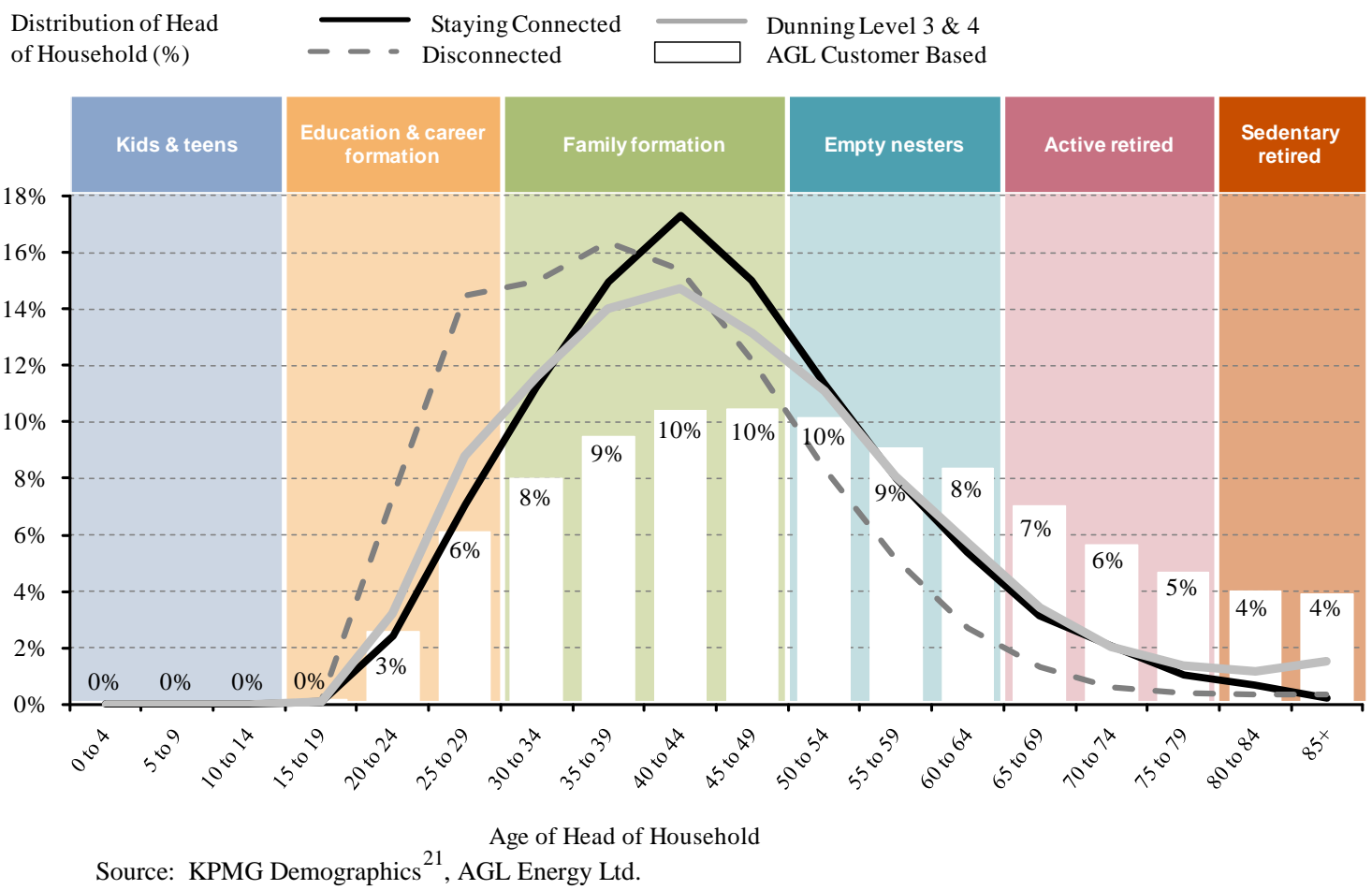

To begin with, in Figure 13 the x-axis measures the Age (in years) of the Head of each Household - that is, the person responsible for paying the household electricity or gas bill. While Age is grouped into 5-year time-buckets, they are further aggregated into six life-stages, or cohorts. The first cohort is 'Kids and Teens' which spans from age 0 to 15 . This is followed by the second cohort, 'Education \& Career Formation" which spans from 16 to 29 years, then "Family Formation" from age 30 to 49 and so on. So for example, if an electricity account holder is 54 years of age, they are allocated to the 50-54 year time-bucket and form part of the "Empty Nester" cohort. The y-axis then measures the distribution of the Head of Households. Key results from Figure 13 are as follows:

1. The distribution of AGL's 2.4 million household customers is represented by the white bar graph series. Energy account holders are dominated by people aged between 30-64, and for obvious reasons, there are no account holders below the age of 15 and only a very small number aged 15-19. The average age of AGL energy customers is 52 years of age.

2. The distribution of AGL's c.8,000 hardship customers, who are registered with our 'Staying Connected' program, are represented by the 'solid black' line series and visibly peak in the Family Formation cohort. The distribution is pronounced in the 40-44 year time-bucket, although the average age of Hardship Customers is 45 years of age.

3. The distribution of AGL's c.380,000 Dunning Level 3 \& 4 customers (who failed to make contact despite being issued with an official Late Payment Notice) are represented by the 'solid grey' line series. They largely follow the distribution of the Staying Connected group, and the average age is also 45 years of age; and finally

\footnotetext{
${ }^{21}$ The authors would like to acknowledge the exceptional work undertaken by Bernard Salt and Sally Mikkelsen (KPMG) in producing Figure 14.
} 
4. The distribution of the c.20,000 Disconnected Customers, who disengaged with AGL, is represented by the 'dashed grey' line series. This group, which has opted not to communicate and has subsequently been disconnected, has an average age of 40 years. The dominant time-bucket is 35-39 years of age, although there is a noticeable pronouncement in the highly mobile "Education and Career Formation” cohort.

In total, about $16 \%$ of AGL Customers display varying signs of hardship. However, this result rises to 1 in 4 households when examining the Family Formation cohort. But while Figure 13 demonstrates that hardship is dominant amongst the Family Formation cohort, it provides little information as to why this is the case. Figures 14-16 provide the requisite insight. In Figure 14, we present the absolute variation in household energy costs by age bucket compared to the average spend of an account holder. Notice that the Family Formation cohort spends considerably more than benchmark, as do the early phase Empty Nesters. All other age groups and cohorts spend less than benchmark. There is also considerable variability of spending on energy amongst the Family Formation cohort. But on average, those in the Family Formation stage have a consumption pattern that is $13 \%$ in excess of benchmark, and this excess rises to almost $30 \%$ in the $41-48$ year age bracket, the mid-point of which, perhaps unsurprisingly, is the average age of hardship customers identified in Figure 13.

\section{Figure 14: Absolute variation in household energy costs}

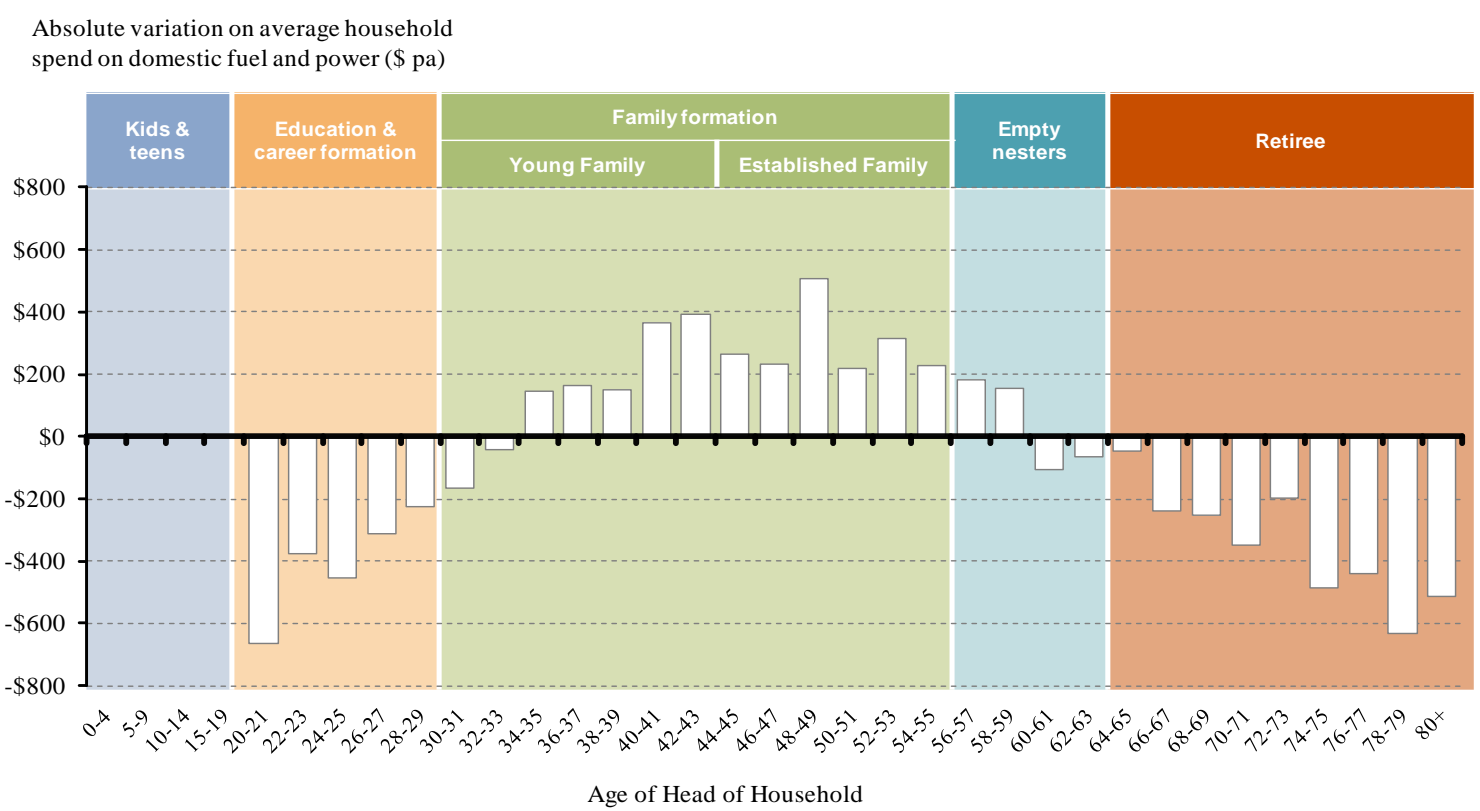

Source: ABS, KPMG Demographics.

In Figure 15, we introduce the average size of Households and a somewhat unusual measure of household income, the 'average per person income, per household'. So in other words, if a family comprising two adults and two children had a combined weekly income of $\$ 1,000$, our measure would amount to \$250 per person, per household. Note in Figure 15 that household size (and by deduction, income) peaks in the Family Formation stage, and that income per person per household displays a distinct trough at the same time. While Family Formation income remains elevated by comparison other cohorts, households in that stage have more members, and are consequently more likely to face higher fixed housing costs. 
Figure 15: Average household size and average household income per person

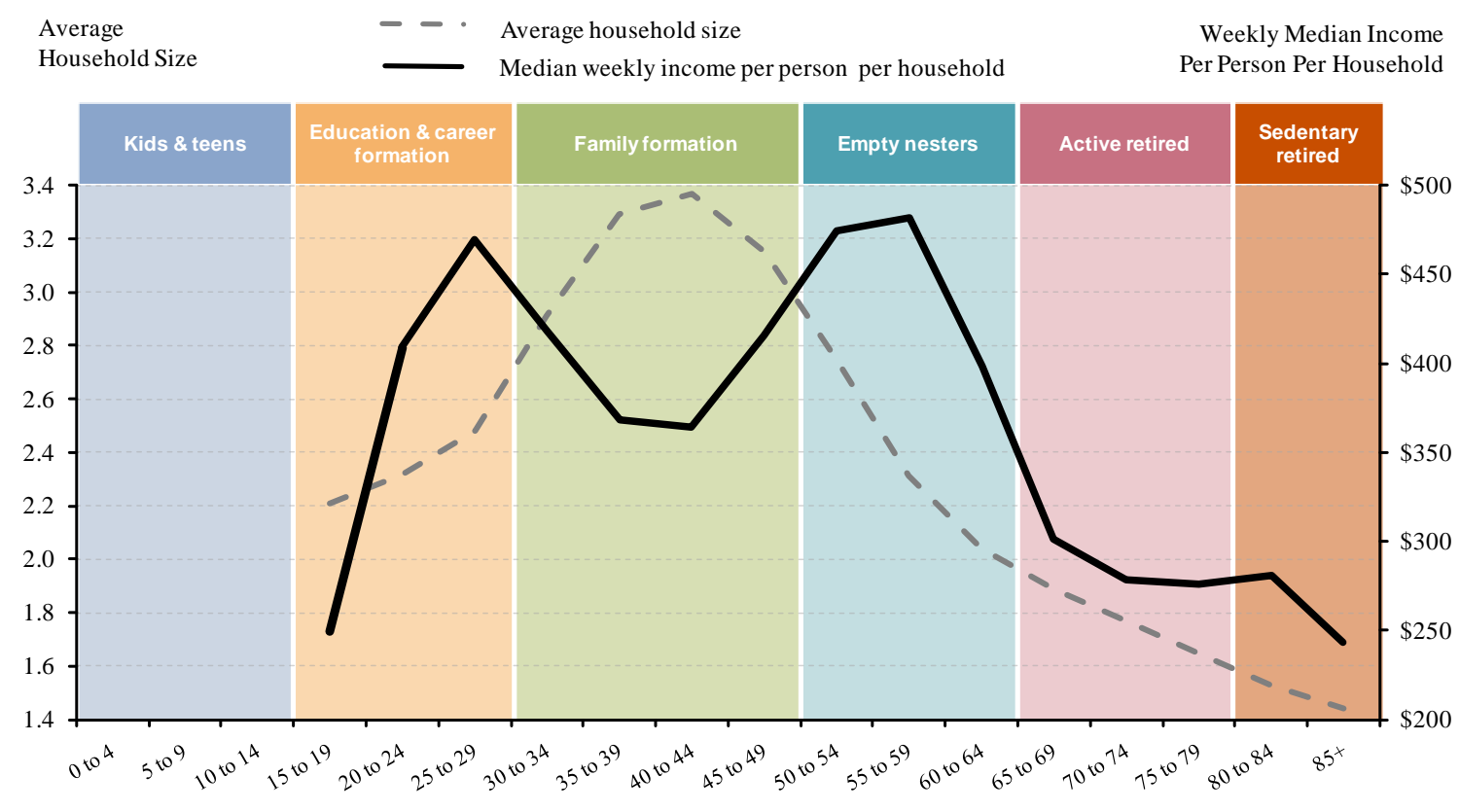

Age of Head of Household

Source: ABS, KPMG Demographics, AGL Energy Ltd.

In Figure 16, we combine Figures 13 and 15, and the reason as to why hardship is congested amongst the Family Formation cohort becomes clearer. Note that our measure of per person income per household has a reverse scale (RHS y-axis), meaning that a rising line equates to falling per person income per household - and in the event, within the Family Formation cohort seems to run almost parallel with the hardship distribution line.

\section{Figure 16: The incidence of household hardship and income per person}

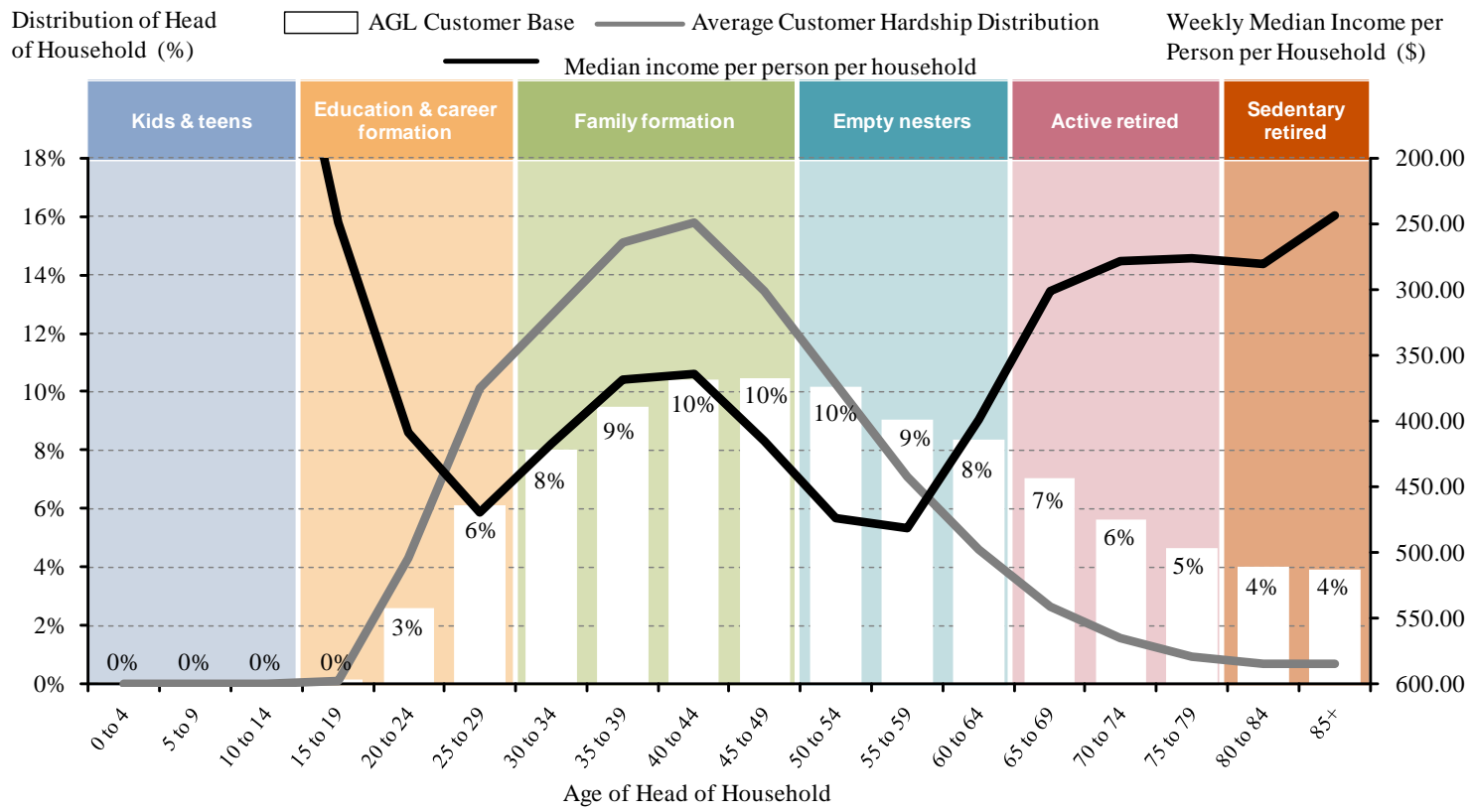

Source: ABS, KPMG Demographics, AGL Energy Ltd.

Weekly per person income per household in the "Family Formation” cohort falls to just \$392 during a phase in life in which few, if any, escape the cost of rent or a mortgage capable of 
housing the average 3.2 person household. As energy economists, we found the results of this quantitative analysis, and the implications for hardship policy, to be startling. The Family Formation cohort are evidently the most proportionately impacted by hardship and the implications are material given that government assistance and concessions in relation to energy supply are not, as far as we are aware, aimed at this group. Our own data on the incidence of hardship and on disconnections clearly provides the appropriate evidence, with about 1 in 4 households in this cohort showing signs of energy account default. This cohort has a number of characteristics that make it unique from others:

1. When households in the Family Formation cohort are experiencing hardship, more Australians are being impacted proportionately. That is, Family Formation households in duress implies that 3.2 people are, on average, in hardship whereas a Sedentary Retired household involves only 1.9 persons, on average.

2. Children are staying at home longer and households with children means bigger and more active houses. As EMCa (2009) observed in their quantitative assessment of energy consumption in Western Sydney, households with 4 bedrooms consumed an average of 8.6MWh per annum, 2.6MWh (43.3\%) more than a 3 bedroom house and 5.2MWh (152.9\%) more than a 2 bedroom house.

3. The average energy account holders in the Family Formation cohort has two or more uncontrollable consumers (i.e. children) who are blissfully unaware and unmoved by the financial impact of their uncoordinated, and in many cases, simultaneous energy consumption decisions arising from the use of computers, game controls, plasma televisions, heating and cooling devices in their household. We know from pilot tariff programs that the number of residents per household is an important indicator of consumption levels.

4. The primary account holder will also hold a sizeable monthly mortgage or incur rental costs commensurate with the requirements of housing adults and children, which distinguishes them from Empty Nesters and Active Retired, for example. Indeed, data made available to the authors from two of the major banks in Australia notes that the size of housing mortgages 'peak' at the age of 45 - the same median age of hardship identified in Figure 16.

The Family Formation cohort comprise $27 \%$ of the customer base and are therefore the dominant market segment. We noted above that the Family Formation cohort also dominate hardship statistics, with about 1 in 4 households showing signs of energy account default. Notice that while the Active Retired cohort has lower per person incomes per household, they are substantially under-represented in Staying Connected, early hardship, and disconnection events. Unlike their Family Formation counterparts, Active Retired are typically able to manage their own energy use down more effectively (i.e. they have no dependent children) although this cohort are also known to be more inclined to simply 'go without' - the incidence and consequences of which we are simply unable to capture or measure. After discussing this limitation with some of our peers at NSW regulatory authority IPART, we consider this to be a significant limitation of our research.

Yet with respect to our underlying thematic, similar findings are being made by researchers examining other areas of social and economic policy. Bradbury (2012) recently noted an inverse correlation in relation to the age of the highest income earner in a household and an inability to pay utility bills - we have reproduced those findings in Figure 17. 
Figure 17: Correlation between ability to pay bills and savings rates by age group

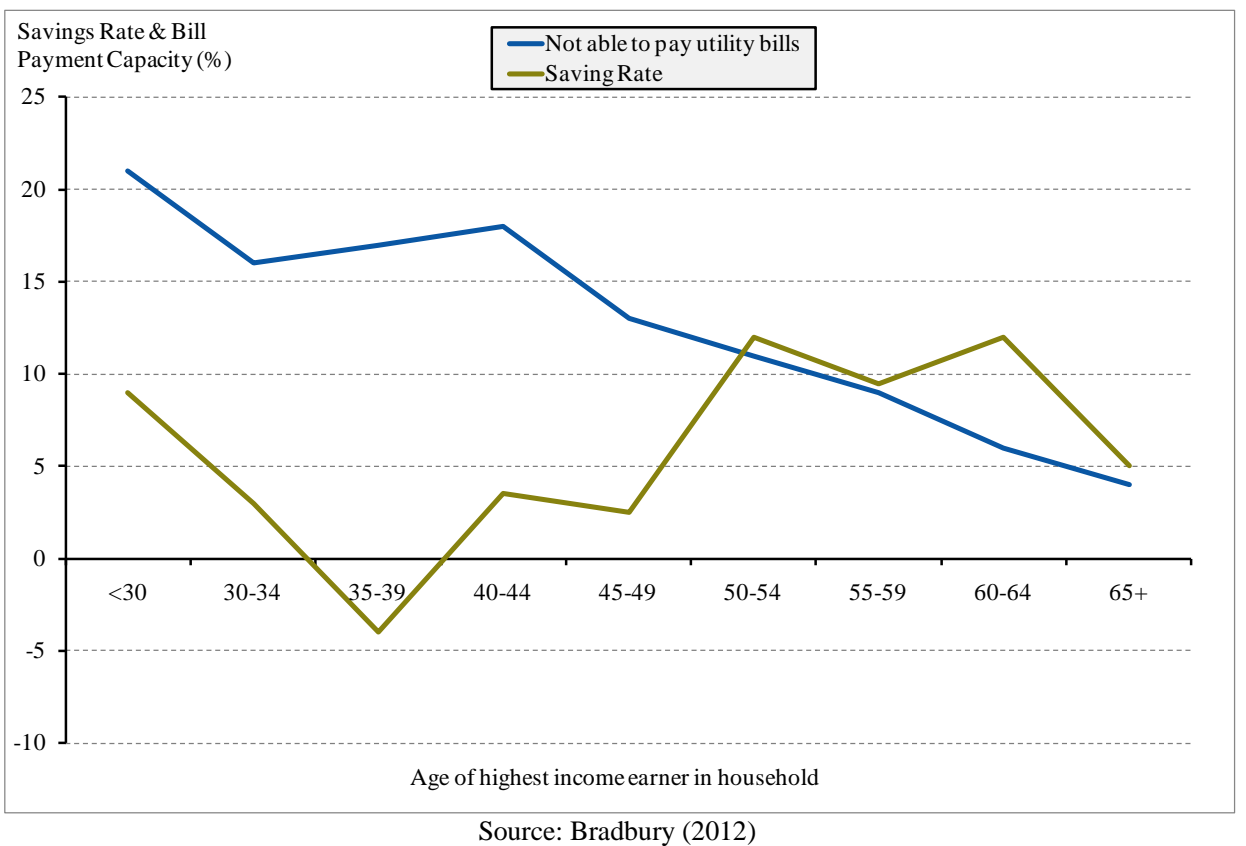

\section{Policy Implications}

Policymakers are acutely aware that Australian electricity prices have been rising rapidly. There have been many public policy reviews but little reform has been implemented. In any event, as we noted at the outset, electricity tariff increases form part of the Consumer Price Index, and household incomes are, on average, rising faster than CPI and the basket of household goods that it represents. Consequently, economists and policymakers generally acknowledge that this poses no visible problem to the overwhelming majority of consumers beyond household budgeting adjustments and inconvenience. For households already in hardship, the issue is considerably more vexed than a budgeting adjustment. It could be argued that the public policy response to date has been limited in scope, and in foresight.

Households in general are nonetheless reacting despite their rising incomes, and the media is focusing on energy price increases and consequently, the political economy of energy pricing in Australia is extremely controversial. Unfortunately, much of the network capital expenditure has led to price increases that have been 'locked-in' in the sense that it has either been approved by regulated prices, or has already been incurred. Accordingly, network service providers will continue to price electricity to recover an economic rate of return on this expenditure. In future, policymakers may consider introducing incentives for network service providers around noncapital expenditure related metrics such as network utilisation. Policymakers could also consider methods of increasing economies of scale such as the NSW Government decision to amalgamate network service providers to reduce unnecessary costs.

We believe that a number of existing policies require re-evaluation regarding their effectiveness in alleviating customer hardship, given the evidence presented in this article. These include (1) the approach to electricity tariffs, metering and billing, (2) concession policies where rebates are provided on household bills; and (3) the funding of hardship policy and the design of energy efficiency policies.

\subsection{The approach to electricity tariffs, metering and billing}

Simshauser and Downer (2012) demonstrated that a shift away from flat tariffs to time-of-use tariffs with critical peak price structures, which requires interval meters, represents good public policy in relation to moderating peak load growth, and in turn, non-trivial components of the 
investment megacycle. ${ }^{22}$ We noted earlier that inclining block tariffs, which can be implemented with existing mechanical meters, are more likely to aggravate the possibility of an energy market death spiral. Rising energy throughput poses no problem per se, but congested time-of-use consumption does. Inclining block tariffs are effective conservation-driven pricing structures, but represent an especially blunt instrument if its intended target is critical event peak loads. More likely is that they will do virtually nothing to remedy the peak load problem as Houthakker (1951, p.5) discovered more than 60 years ago in the case of Britain:

...as demand approaches its maximum only within short periods of the day, these are precisely the periods when the relatively inelastic lighting component is important. Space heating, which has a special responsibility for the present peaks on cold mornings, is probably more sensitive to price changes than lighting but the elasticity varies with the time of day, and may be small on such mornings. Consumers will naturally economise at the times least inconvenient to them, and these are likely to be off-peak periods when no reduction of demand is required...

While Houthakker (1951) was analysing the electricity demand of a cold climate electricity system in a 1950s British household, his observations are equally applicable to hot climate systems and air conditioning loads, which have a special responsibility for the present peaks on hot days. Reductions in energy demand, but not peak demand, arising from inclining block tariffs will hence result in further network tariff rebalancing to offset volumetric losses. This is not to say that tariff reforms should not be pursued - there are indeed sound public policy reasons for doing so. However, the focus must be on some form of time-based differentiated pricing.

Most households in hardship experience financial difficulty when forced to digest unpredictable and high-cost invoice events such as a quarterly summer electricity bill. More regular invoicing would make household budgeting adjustment processes substantially easier. This is of course another benefit of introducing advanced metering infrastructure. Apart from facilitating critical peak pricing, remotely read interval meters enable electricity billing to be re-set to a monthly cycle, as is the case with telecommunications. Currently, energy invoices to customers are issued on a quarterly basis to match the frequency of physically reading mechanical meters. If smart meter rollouts are likely to be protracted, we believe that some form of monthly accrual invoicing with quarterly final settlement may represent a sensible interim solution for households.

\subsection{Concession policies}

In relation to dealing with the symptoms of rising energy prices, concessions frameworks have been in place since the deregulation of energy markets in the 1990s. Generally, they are funded by the Commonwealth or State Governments and implemented through a rebate paid on an electricity or gas bill. Other forms of important and necessary concessions exist which tend to be emergency in nature, such as the NSW Government's Energy Accounts Payment Assistance concession (administered by community groups) to customers facing disconnection, or very specific to particular groups such as medical or life support rebates. Table 1 provides a summary of the main concessions payable to eligible consumers.

\footnotetext{
22 One reviewer made the observation that smart metering technologies also facilitate better pricing of distributed generation - an important point given $2500 \mathrm{MW}$ of recently installed embedded solar PV in Australia.
} 
Table 1: $\quad$ State based energy (electricity and gas) concessions ${ }^{23}$

\begin{tabular}{cl}
\hline State & Summary of Standard Energy Concessions (2013) \\
\hline Victoria & $\begin{array}{c}\text { Annual Electricity Concession: } 17.5 \% \text { off consumption and service charges } \\
\text { Winter Energy Concession: } 17.5 \% \text { off consumption and service charge } \\
\text { Off Peak Concession: } 13 \% \text { off the off-peak usage }\end{array}$ \\
New South Wales & $\begin{array}{c}\text { Low Income Household Rebate: } \$ 215 \text { annual rebate } \\
\text { Family Energy Rebate: } \$ 35 \text { up to } \$ 70 \text { annually }\end{array}$ \\
Queensland & $\begin{array}{l}\text { Electricity Rebate: } \$ 0.5740 \text { per day }(\$ 209.51) \\
\text { Reticulated Natural Gas Rebate: } \$ 0.16 \text { per day (\$58.40) }\end{array}$ \\
& SA Energy Rebate: $\$ 165$ annual rebate \\
\hline
\end{tabular}

In all states except Victoria, concessions are paid as a lump sum irrespective of consumption. This is somewhat problematic given consumption patterns of the Family Formation cohort - they are, after all, the largest users of energy. This is not controversial given the need for space heating and cooling with young children and the proliferation of new appliances and information technology generally. Table 2 provides the quantitative evidence by breaking down consumption by the age of the person most responsible for paying the energy bill within a home.

Table 2: Household consumption by account holder's age (\%)

\begin{tabular}{lccccc}
\hline Age & $<4$ MWh & 4-6 MWh & $6-8$ MWh & $8-12$ MWh & $>12$ MWh \\
\hline 18-34 years & 3 & 9 & 12 & 13 & 3 \\
35-55 years & 23 & 27 & 32 & 33 & 49 \\
55-64 years & 23 & 21 & 20 & 24 & 31 \\
$>$ 65 years & 51 & 43 & 35 & 29 & 17 \\
\hline \multicolumn{7}{c}{ Source: IPART (2010). }
\end{tabular}

The analysis in Table 2 has been adapted from a household energy and water survey completed by NSW regulator IPART relating to residents in Sydney and the Blue Mountains. Note the extent to which high consuming household account holders are between 35 and 55 years of age, and so the use of non-consumption based concessions is likely to result in payments being disproportionately skewed towards non-Family Formation segments in relative terms. Since the number of persons in Family Formation households is by definition materially larger than other cohorts, payments are also being skewed away from a greater number of recipients. Based upon the evidence presented in relation to the incidence of customer hardship and consumption patterns in Table 2, it would appear prudent for policy makers in other states to consider adopting a variant of the Victorian consumption-based framework, ideally linking fixed payments to the number of persons per household. ${ }^{24}$

Another key issue in relation to the provision of energy concessions relates to eligibility criteria, which as Table 1 notes varies by jurisdiction. In most states, eligibility is defined as being in possession of a Centrelink Healthcare card, a Centrelink Pensioner card or a Department of Veteran Affairs (pensioner or war widow) card. These cards are not specific to any particular age group, but are reflective of providing assistance to particular groups in the community who are presumably in hardship or vulnerable in broader terms. Even more problematic is that some

\footnotetext{
${ }^{23}$ Further information on concessions is available at: http://www.agl.com.au/home/billing-and-payments/Pages/concessions-rebatesand-grants.aspx, Accessed online on 27 December 2012.

${ }^{24}$ We are reluctant to suggest a pure consumption-based framework - enough distortions already exist vis-a-vis residential tariffs. A consumption-based approach may also provide an unhealthy incentive for households to over-consume, and for State Governments to further suppress cost-reflective tariffs movements through strategic use of retail price regulation in an attempt to minimise hardship funding costs.
} 
existing concessions are provided irrespective of whether hardship is likely to be an issue. For example, in Queensland, rebates are provided to all holders of Queensland Government Seniors Cards.

Existing eligibility criteria may well have been effective in preventing customer hardship in other cohorts, and may explain the counter-intuitive results arising from our analysis. However, there is no eligibility criteria designed to identify hardship within the Family Formation cohort. We consider this to be a 'gap' in energy policy hardship frameworks. Appendix I provides geographical maps of the four main capital cities within the NEM, and identifies hardship 'hotspots' from an energy account perspective. While we would not purport that these maps are definitive, they provide a useful starting point for policymakers to consider - at least based on AGL's experience in serving about a quarter of the energy customers on Australia's eastern seaboard.

We believe that there is scope for a complete redesign of the State-based and national concessions framework to achieve a greater focus on customers in genuine hardship. A 'trigger' that seems to the authors as worthy of further analysis is those who qualify for Family Tax Benefit - Part A, the definition of which seems to fit low-income families, most likely within the Family Formation cohort.

\subsection{The funding of hardship policy and energy efficiency schemes}

Another area requiring the attention of policymakers relates to the source of funding, and specifically, the use of levies that use customer energy consumption as the collection device. Nelson, Simshauser and Kelley (2011) and Nelson, Simshauser and Nelson (2012) demonstrated the regressive nature of government policy measures funded through levies on all customer electricity bills. These articles examined the impacts of "Premium" Feed-in Tariffs - with a focus on how these premiums were being funded. The key finding was that "the effective taxation rate for low income households is three times higher than that paid by the wealthiest households"

(Nelson et al, 2011, p. 113). While these articles examined the adverse effects of Premium Feedin Tariffs, the results are directly applicable to any levy or indirect tax applied to energy customers, using household consumption levels as the revenue raising device. ${ }^{25}$

It is in this context that findings from such research provide valuable insights for policymakers in relation to other areas of energy policy. For example, energy efficiency schemes in Victoria, NSW and South Australia are aimed at reducing energy consumption through a mandated obligation on energy retailers (i.e. by procuring specified energy savings). The upfront costs of these scheme obligations are ultimately passed through to all end-consumers in the form of higher energy prices. South Australian policymakers have tried to balance these effects by placing specific obligations on energy retailers to provide energy audits for low-income consumers - a policy adjustment we believe to be entirely sensible, if not desirable.

Energy efficiency schemes are an especially vexed area of policy because they also need to ensure that the correct demand segment is being targeted. Reducing peak demand will benefit all consumers because it will have the effect of reducing future resource requirements throughout the supply chain. Reducing energy consumption without reducing peak demand will not ${ }^{26}$ - the electricity system is now very poorly utilised due to rising peak demand as Simshauser and Nelson (2013) note, and thus reducing 'non-critical event' demand would lead to a further

\footnotetext{
${ }^{25}$ A valid criticism of the work of Nelson et al (2011) and Nelson et al (2012) is that they failed to consider temporal dynamic benefits associated with the development of technology which over time becomes available to all consumers at a lower cost than it otherwise would have been. The issue here is that the relationship between taxation and innovation subsidies is a complex one and a short run partial static equilibrium analysis can deliver misleading results by comparison to a more dynamic long run general equilibrium analysis.

${ }^{26}$ Although as one reviewer noted, it may reduce negative production externalities - greenhouse gas emissions.
} 
deterioration in utilisation rates, thus increasing costs, not decreasing them. As such, a misguided energy efficiency scheme can be detrimental to all consumers, including business and industrial consumers. In our view, policymakers should focus on settings that encourage peak demand reduction, wise energy use, energy efficiency appliances and appropriate building standards.

Regardless, and noting that there is frequently a trade-off between efficiency and social equity, policymakers need to be aware of the fact that where the funding of policy initiatives is raised via levies on all energy consumers, it results in a form of outsourced taxation that is regressive in nature. Such concepts are not difficult to demonstrate. In Tables 3 and 4, we analyse NSW and Queensland household survey data and apply a 'tax' or levy on all households based on their level of electricity consumption. The results of this analysis demonstrate that when taxes are added to electricity bills based on consumption levels, whether designed to alleviate hardship, enhance energy efficiency or fund premium Feed-in Tariffs, their impact is fundamentally regressive and therefore counter-productive (at least in the short-term). ${ }^{27}$ Notice from Table 4 that the effective tax rate for households earning less than $\$ 31,000$ per annum, given their consumption levels, is $0.20 \%$. This is more than three times higher than those on incomes greater than $\$ 151,000$ per annum who, despite consuming more energy, face an effective tax rate of just $0.06 \%$ given the combination of consumption and income levels.

Table 3: $\quad$ NSW consumption survey data by income and implied tax rate

\begin{tabular}{cccccccc}
\hline Income & $<4 \mathrm{MWh}$ & 4-6 MWh & $6-8 \mathrm{MWh}$ & $8-12 \mathrm{MWh}$ & $>$ 12 MWh & Mean & Tax Rate \\
\hline$<\$ 34 \mathrm{k}$ & 109 & 87 & 63 & 48 & 10 & 6.03 & 0.18 \\
\$34k-\$62k & 57 & 47 & 51 & 66 & 20 & 7.14 & 0.15 \\
\$62k-\$130k & 21 & 31 & 43 & 57 & 54 & 8.53 & 0.09 \\
$>$ \$130k & 7 & 24 & 16 & 33 & 40 & 8.92 & 0.07 \\
Not disclosed & 23 & 20 & 15 & 35 & 21 & 7.89 & N/A \\
\hline \multicolumn{7}{c}{ Source: IPART, AGL Energy Ltd. }
\end{tabular}

Table 4: QLD consumption survey data by income and implied tax rate

\begin{tabular}{cccccccc}
\hline Income & $<4$ MWh & 4-6 MWh & 6-8 MWh & 8-12 MWh & $>12$ MWh & Mean & Tax Rate \\
\hline$<$ \$31k & 50 & 55 & 47 & 28 & 9 & 6.31 & 0.20 \\
\$31k to \$71k & 59 & 90 & 103 & 87 & 23 & 7.05 & 0.14 \\
\$11k to \$151k & 42 & 68 & 93 & 106 & 44 & 7.78 & 0.07 \\
$>$ \$151k & 4 & 4 & 11 & 13 & 18 & 9.18 & 0.06 \\
Not disclosed & 24 & 34 & 33 & 42 & 11 & 7.28 & N/A \\
\hline
\end{tabular}

Australian policymakers should observe the evidence, and the mistakes, made in other jurisdictions. In the British energy market for example, stakeholders are now urging policymakers to reconsider the current "fuel poverty" policy settings because of their regressive nature. There, a substantial proportion of hardship funding is sourced from levies on all consumer bills. The Community Energy Savings Program (CESP) requires electricity generators and retailers to contribute funds to alleviate fuel poverty - one British energy retailer alone levied $£ 500$ million on their customer base in a single year to meet the requirements of the government's CESP. This policy is aggravating the incidence of hardship because, as the CESP is levied on electricity users, it pushes a fresh bracket of households into hardship as the levy rises, which may not have occurred in the absence of the scheme.

Economists have been increasingly been turning their attention to the regressive nature of such policies (see for example Stockton and Campbell, 2011; Hotten, 2008). In addition to criticisms

\footnotetext{
${ }^{27}$ A reviewer of this article observed, State Government Owned network operators raise finance at cheaper rates than commercially equivalent counterparts. This 'outsourced' taxation which is returned to government as dividends is effectively a regressive form of taxation.
} 
in relation to funding sources, Stockton and Campbell (2011, p.4) found that some measures are poorly designed to the point that "the innate injustice of a regressive funding mechanism is compounded by lack of equal access to the potential benefits." Based upon this analysis, it could be argued that the Commonwealth Government should assume control of energy concessions to deliver a nationally consistent framework utilising progressively funded taxation revenue.

\section{Concluding Remarks}

This article has reviewed the recent increase in electricity prices in Australia, driven by higher fuel prices and an investment megacycle. At the same time, Australian electricity demand has declined for the first time since World War II. However, it is unclear that peak demand will decline into the future. But the persistent use of 'flat' or average tariffs, as distinct from time-ofuse plus critical peak prices, is unlikely to lead to improvements in system utilisation. A progressively worsening capital utilisation rate and even modest growth in peak demand is, over time, capable of setting-off a whole new cycle of price increases. To be sure, such an outcome is avoidable. The introduction of advanced metering infrastructure and peak, off-peak and critical peak pricing structures would almost certainly avert the onset of such a scenario. ${ }^{28}$

This article has also demonstrated that hardship policy is not necessarily reaching the demographic where energy consumption-related hardship is most prevalent. 'Family Formation' households are disproportionately represented in our hardship statistics relative to other cohorts. These households are characterised by higher numbers of people within the household, nonincome earning dependants and less discretionary energy use. While other demographic groupings may be experiencing other types of hardship (e.g. under-consumption of energy), households in the Family Formation cohort are most at risk of experiencing energy related financial hardship. Our results are consistent with other research related to identification of the demographic incidence of hardship. Winestock (2012) summarised this thematic of Family Formation being at greater risk when noting that "pensioner's costs are rising at the slowest rate on record". Accordingly, a review of concessions policy more generally seems to us to be important, in addition to ensuring that funding of improvements are derived from progressive sources such as government balance sheets, not regressive sources such as household electricity bills.

\section{References}

ABARE: Australian Bureau of Agricultural and Resource Economics, (2010), "End use energy intensity in the Australian economy”, ABARE-BRS Research Report 10.08, Canberra.

AEMC: Australian Energy Market Commission, 2011, "Strategic Priorities for Energy Market Development”, AEMC Discussion Paper, Sydney.

AEMO: Australian Energy Market Operator, 2012, National Electricity Forecasting Report 2012, Available at: http://aemo.com.au/Electricity/Planning/Forecasting/National-Electricity-Forecasting-Report2012. Accessed online on 28 November 2012

BCG: Boston Consulting Group, 2011, “Navigating the New Consumer Realities”, BCG Publication, available at http://www.bcg.com/

Booth, R. (2000), Warring Tribes: the Story of Power Development in Australia, Bardak Group, Perth.

\footnotetext{
${ }^{28}$ One reviewer made the observation that reform has commenced in relation to the introduction of smart metering technologies. However, a mandated smart meter roll out has only occurred in Victoria. While reform has been agreed to in relation to competitive adoption of smart metering technologies, it is yet to be implemented.
} 
Bradbury, B., (2012), "Saving the young from superannuation”, Club Troppo, http://clubtroppo.com.au/2012/01/05/saving-the-young-from-superannuation/, Accessed on 10 January 2012

Commonwealth Government, (2011), Securing a clean energy future: The Australian Government's Climate Change Plan, Canberra

CSIRO, 2010, “Our future world: trends, risks and scenarios”, CSIRO Publication, Melbourne.

EMCa: Energy Market Consulting associates, (2009), "Smart Meter Consumer Impact: Initial Analysis - a report to the Ministerial Council on Energy”, EMCa Publication, Sydney.

Energex, (2010), 2010 Queensland Household Energy Survey, Brisbane.

Energex, (2012), “DSP3 - the Power of Choice - Role of Pricing \& Technology”, AEMC Power of Choice Conference Presentation, 19 April 2012, Energex Publication, Brisbane.

Gibbs, R. 2011, “Global and Australian Economic and Business Outlook”, Macquarie Economics Research, Sydney.

Hotten, R. (2008), "Fuel poverty levy hits snag with power industry”, The Telegraph, 17 November 2008, http://www.telegraph.co.uk/finance/newsbysector/utilities/3474224/Fuel-poverty-levy-hits-snags-withpower-industry.html, accessed on 11 January 2012

Houthakker, H. (1951), “Electricity tariffs in theory and practice”, The Economic Journal, 61(2): 1-25.

IES: Intelligent Energy Systems, (2013), “What is driving the decline in electricity demand?”, Insider, Issue 14, pp 1-8.

Independent Pricing and Regulatory Tribunal, (2010), "Residential energy and water use in Sydney, the Blue Mountains and Illawarra”, IPART Research Paper, Sydney.

Independent Pricing and Regulatory Tribunal, (2012), “Changes in regulated electricity retail prices from 1 July 2012”, IPART Publication, Sydney.

James, C. (2009), “Australian homes are the biggest in the world”, Switzer, Available at http://www.switzer.com.au/business-news/news-stories/australian-homes-are-biggest-in-the-world/

Kellow, A. (1996), Transforming Power - the Politics of Electricity Planning, Cambridge University Press, Cambridge.

IMF: International Monetary Fund, 2009, “World Economic Outlook - Crisis and Recovery”, International Monetary Fund Publication, Washington. Available at http://www.imf.org/

Nelson, T. (2012), "2011 PESA industry review: securing gas supplies for domestic consumption in the long term”, APPEA 2012 - Journal and Conference Proceedings, Vol.52, pp. 105-114

Nelson, T., Simshauser, P. and Kelly, S. (2011) "Australian residential solar Feed-in Tariffs: industry stimulus or regressive form of taxation?", Economic Analysis and Policy, 41(2): 113-129.

Nelson, T., Simshauser, P. and Nelson, J. (2012), " Queensland Solar Feed-In Tariffs and the Merit-Order Effect: Economic Benefit, or Regressive Taxation and Wealth Transfers?”, Economic Analysis and Policy, 42(3): 277-301

Orchison, K. (2012), “Assessing an assessment”, This is Power Blog, http://www.coolibahconsulting.com.au/TiP/2012/01/09/assessing-an-assessment/, Accessed on 10 January 2012 
QCA: Queensland Competition Authority, (2013), “Estimating a fair and reasonable Solar PV Feed-in Tariff for Queensland”, QCA Publication, Brisbane.

Reinhard, C. and Rogoff, K. 2009, This time is different, Princeton University Press, Princeton.

Severance, C. 2011, "A practical, affordable (and least business risk) plan to achieve $80 \%$ clean electricity by 2035”, The Electricity Journal, 24(6): 8-26.

Simshauser, P. and Catt, A. (2012), "Dividend policy, energy utilities and the investment megacycle”, The Electricity Journal, 25(3):4, 63-87.

Simshauser, P. and Downer, D. (2012), "Dynamic pricing and the peak load problem”, Australian

Economic Review, 45(3): article in-press.

Simshauser, P. and Laochumnanvanit, K. 2012, "The political economy of regulating retail electricity price caps in a rising cost environment”, The Electricity Journal, 25(9): 48-66.

Simshauser, P. and Nelson, T. 2013, “The outlook for residential electricity prices in Australia's National Electricity Market in 2020”, The Electricity Journal, article in-press.

Simshauser, P., Nelson, T. and Doan, T., (2011a) “The Boomerang Paradox Part I: how a nation's wealth is creating fuel poverty”, The Electricity Journal, 24(1): 72-91.

Simshauser, P., Nelson, T. and Doan, T., (2011b) “The Boomerang Paradox Part II: policy prescriptions for reducing fuel poverty in Australia”, The Electricity Journal, 24(2): 63-75.

Stiglitz, J. (2010), Freefall, Allen Lane, London.

Stockton, H \& Campbell, R. (2011), “Time to reconsider UK energy and fuel poverty policies?”, Joseph Roundtree Foundation Paper, http://www.jrf.org.uk/sites/files/jrf/fuel-poverty-policy-summary.pdf accessed on 11 January 2012

Winestock, G. (2012), "Pensioners ahead in cost of living stakes”, Australian Financial Review, 3 May, p. 16 


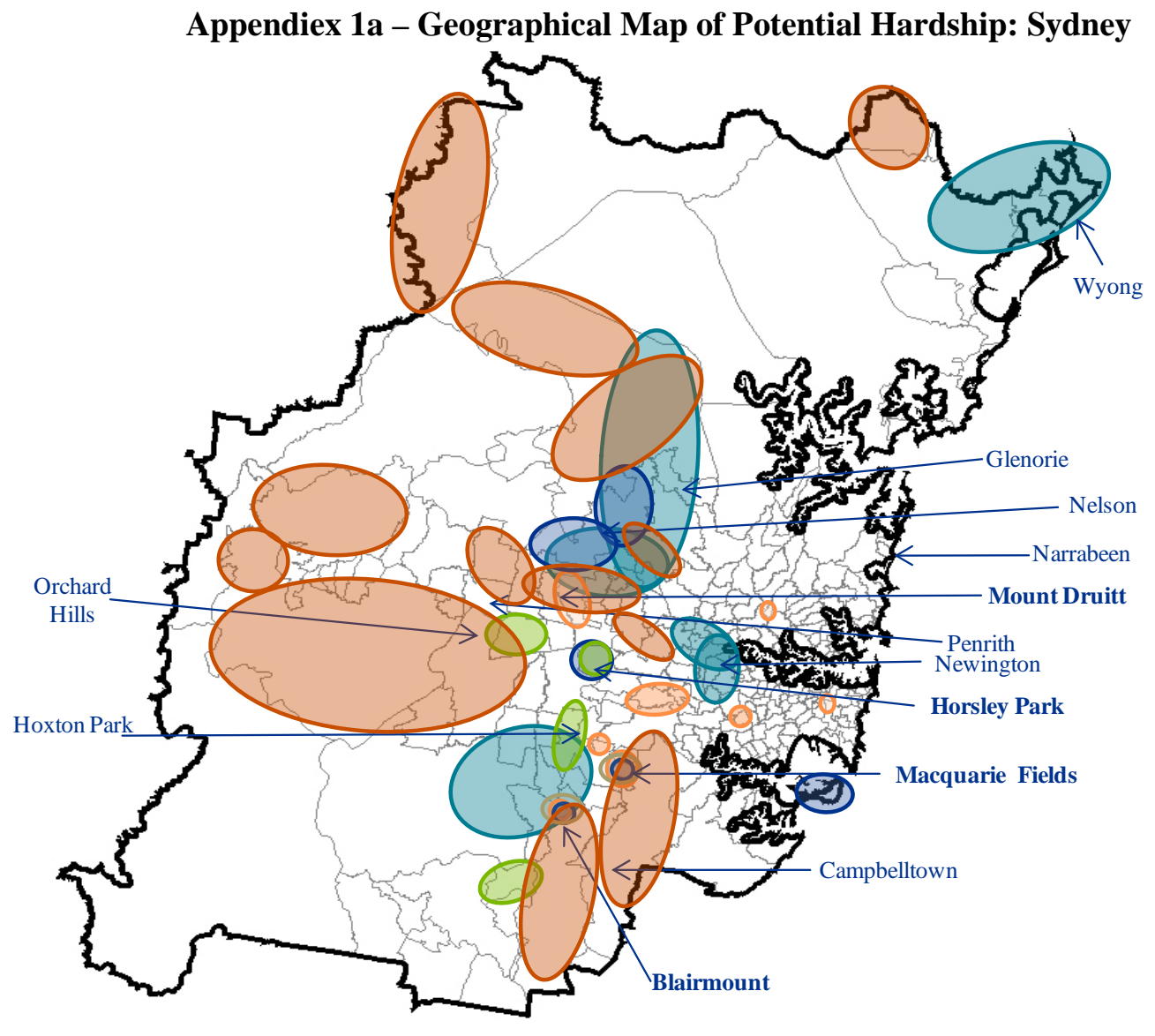

High concentration of:

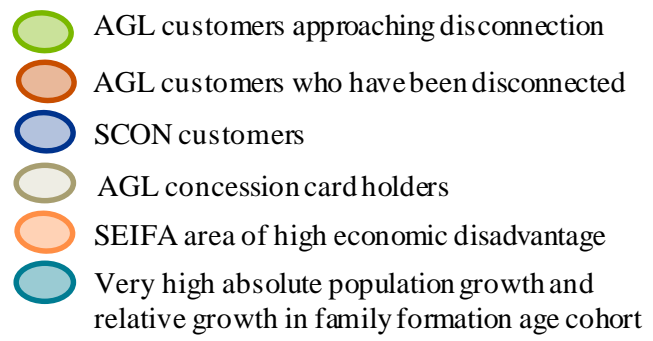

Source: KPMG Demographics, AGL Energy Ltd, based on data from the ABS, customised projections prepared for the Department of Health and Ageing by the ABS 


\section{Appendiex 1b - Geographical Map of Potential Hardship: Southeast Queensland}

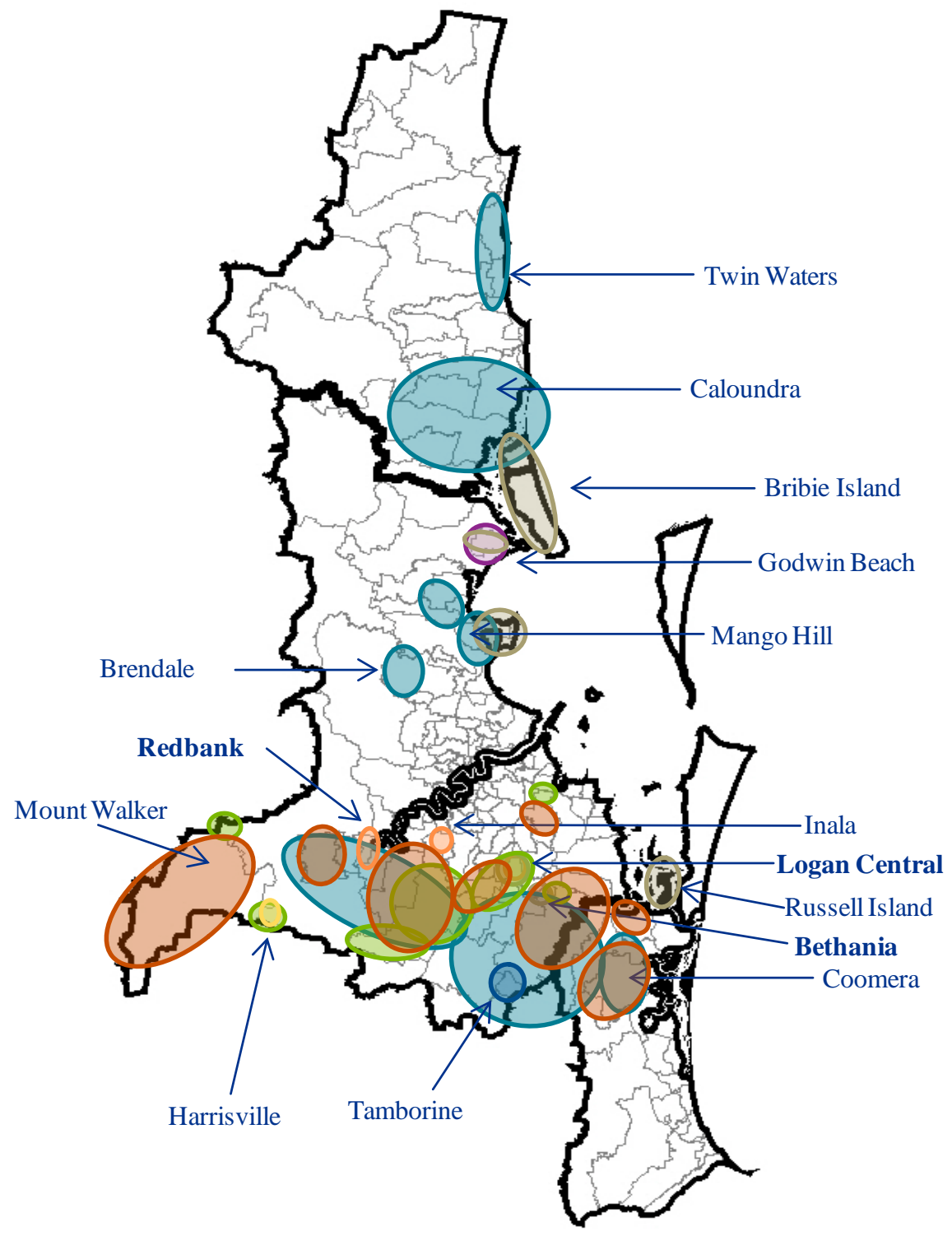

High concentration of:

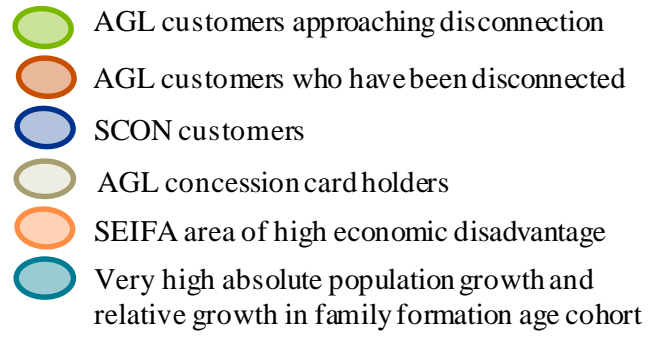

Source: KPMG Demographics, AGL Energy Ltd, based on data from the ABS, customised projections prepared for the Department of Health and Ageing by the ABS 


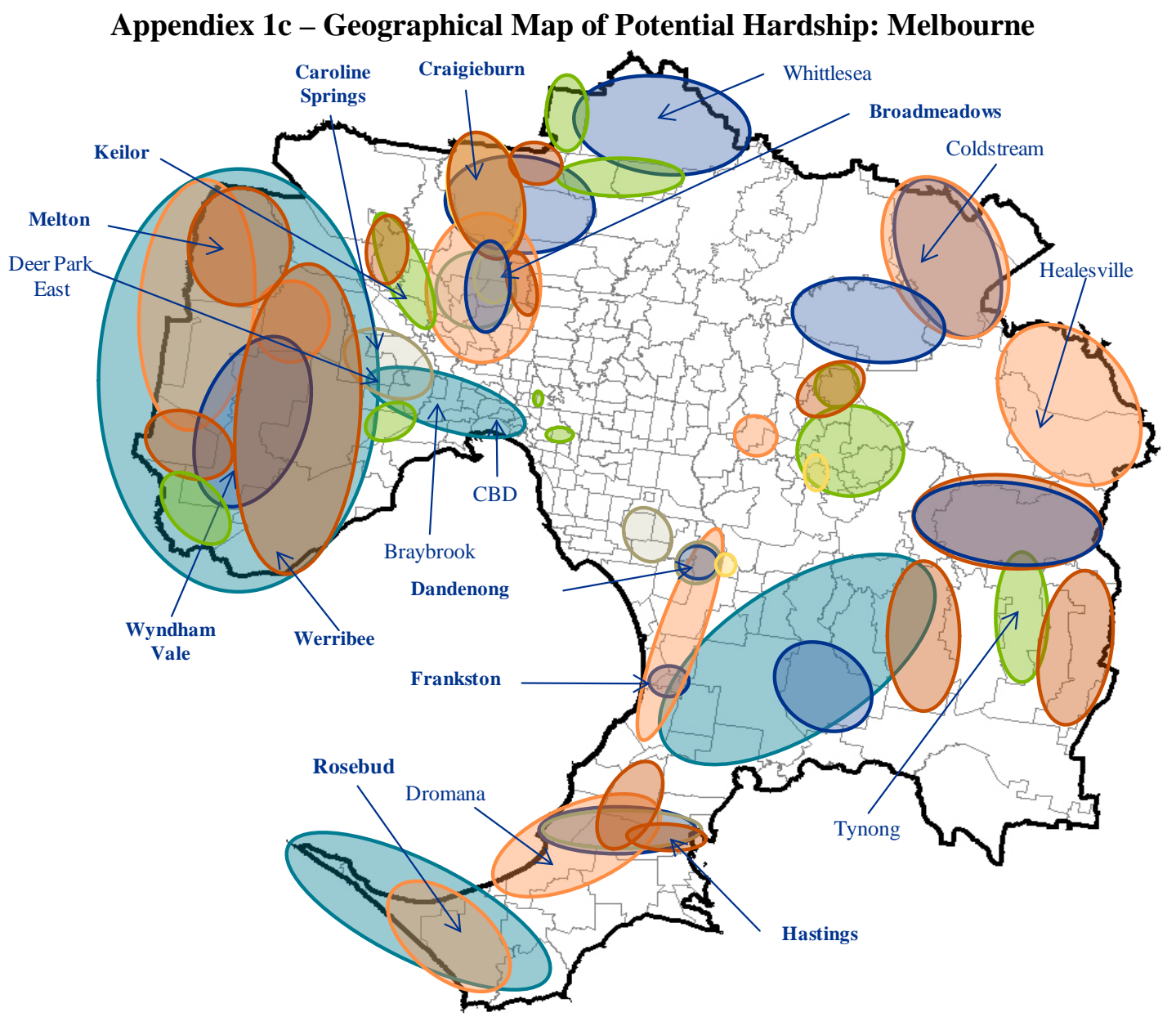

High concentration of:

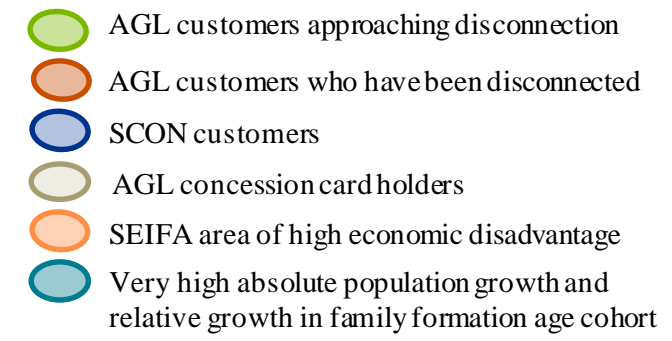

Source: KPMG Demographics, AGL Energy Ltd, based on data from the ABS, customised projections prepared for the Department of Health and Ageing by the ABS 


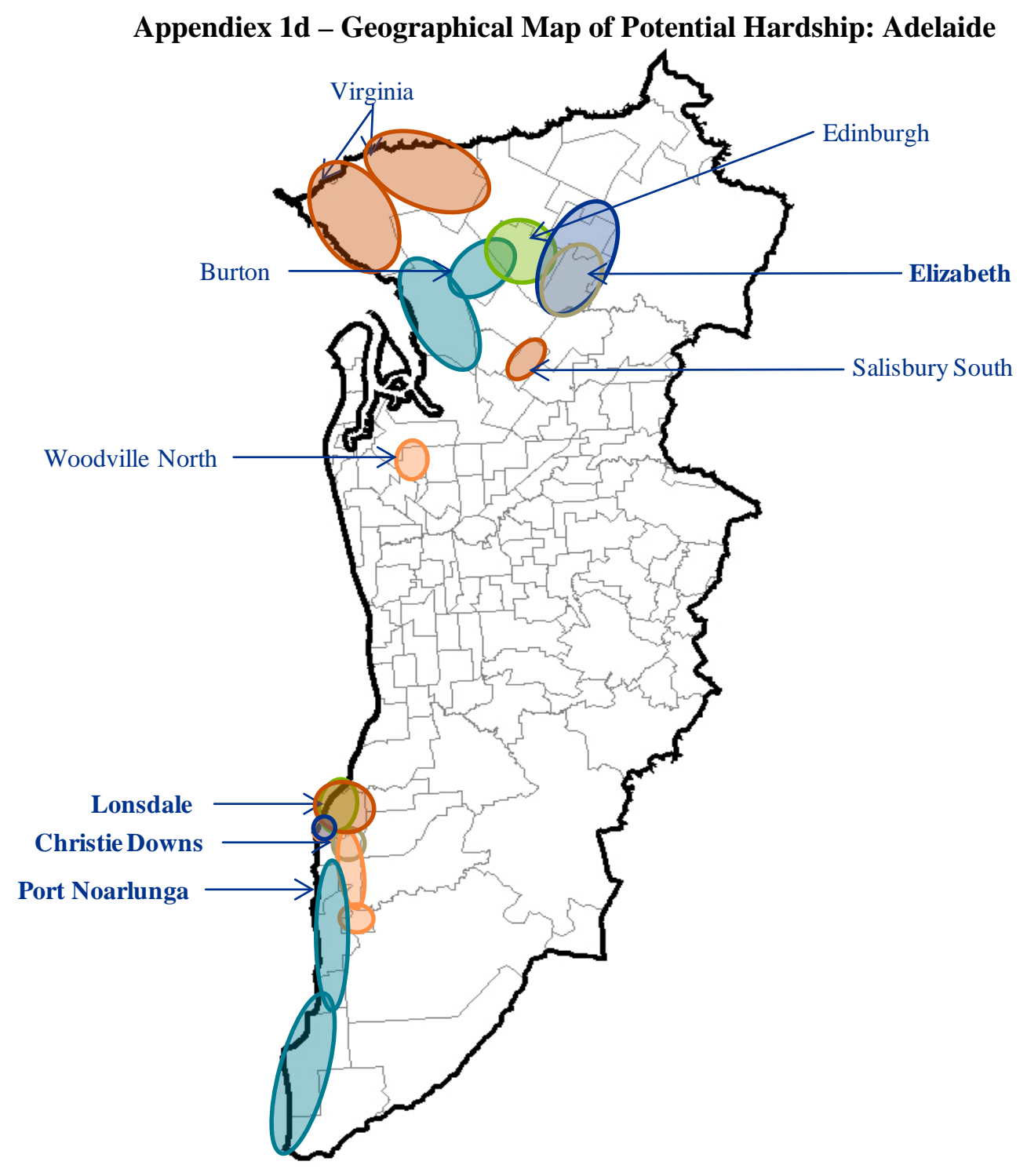

High concentration of:

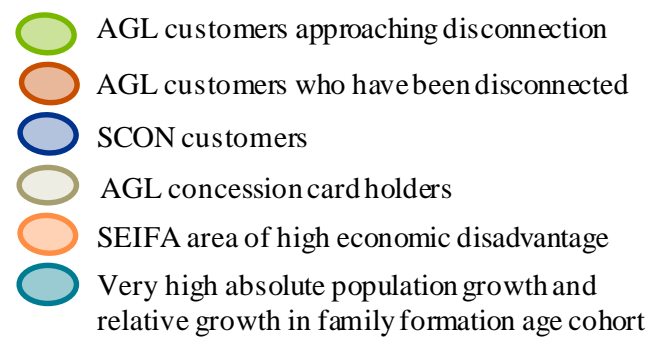

Source: KPMG Demographics, AGL Energy Ltd, based on data from the ABS, customised projections prepared for the Department of Health and Ageing by the ABS 